\title{
Travma Sonrası Stres Bozukluğunda EMDR Uygulamalarının Etkililiğine İlişskin Çalışmaların Gözden Geçirilmesi
}

\author{
Alperen Güçlü ${ }^{1}$ \\ Özden Yalçınkaya Alkar² \\ Ankara Yıldırım Beyazıt Üniversitesi \\ Ankara Yıldırım Beyazıt Üniversitesi
}

\begin{abstract}
Özet
Travma sonrası stres bozukluğu (TSSB), travmatik bir olay sonrası olaya ilişkin görüntüler (flashback), huzursuzluk, irkilme, biliş ve duygudurum değişiklikleri gibi semptomlarla karakterize, hayatın birçok alanında işlevselliği olumsuz yönde etkileyen psikolojik bir bozukluktur. Ayrıca bozukluk yüksek eştanı oranlarına sahiptir ve bu oldukça zorlayıc1 olabilmektedir. İntihar olasılığı da her zaman için mevcuttur. Bir bütün olarak tüm bu bilgiler, TSSB tedavisinin önemine işaret etmektedir. TSSB tedavisi için bilişsel davranış̧̧ terapi, diyalektik terapi, maruz bırakma gibi birçok tedavi modeli önerilmiştir ve bunların etkililiği kanıtlanmıştır. Göz hareketleriyle sistematik duyarsızlaştırma ve yeniden işleme (EMDR) de TSSB tedavisinde son yıllarda önerilen bir terapi tekniğidir. EMDR, birçok bozukluğun tedavi sürecine kolayca uyarlanabilmektedir ve bu bağlamda popülerliği giderek artmaktadır. Buna karşllık görece yeni bir tedavi modelidir ve etkileri tam olarak aydınlatılamamıştır. Özellikle tekniğin etki mekanizması konusunda tartışmalar mevcuttur. Ayrıca bazı uzmanlar EMDR'ın diğer tekniklerden farkı olmadığını ancak onların tamamlayıcısı olabileceğini belirtmektedir. Bu bağlamda EMDR'ın TSSB tedavisindeki kullanımı düşündürücüdür. EMDR, gerçekten de TSSB tedavisinde etkili bir yöntem midir? Bu soru bağlamında bu yazının amacı TSSB tedavisinde EMDR'ın uygun ve etkili bir müdahale olup olmadığına ilişkin araştırma bulgularının değerlendirilmesidir. EMDR'ın etkililiğine ilişkin olarak etkililik oranları ve tedaviyi bırakma (dropout) oranlarını içeren birçok çalışma incelenmiştir. Çalışmaların ortak bulgusu, EMDR'ın TSSB ve eşlik eden tanıları hızlı bir biçimde iyileştirebildiği ve iyileşmenin bir yıla kadar korunabildiğidir. Bu bağlamda EMDR'nn TSSB için uzun süreli etkili bir müdahale yöntemi olabileceği düşünülmektedir.
\end{abstract}

Anahtar kelimeler: Travma, stres, EMDR, etkililik, bırakma oranları

\begin{abstract}
Post-traumatic stress disorder (PTSD) is a disorder characterized by symptoms such as flashbacks, restlessness, startle, cognition-mood changes after traumatic events and negatively affects functionality in many areas of life. Also, disorder has high comorbidity-rates, and this can be quite challenging. There is always the suicide possibility. All this information as a whole points to the importance of PTSD treatment. Many the rapytechniques such as cognitive-behavioral therapy, dialectic therapy, exposure, have been proposed for PTSD, and their effectiveness has been proven. Eye-movement desensitization and reprocessing (EMDR) is also a techniquere commended intreatment of PTSD in recent years. EMDR can be easily applied to many disorder streatment processes and in this context, its popularity is increasing. Where as, it is relatively new treatment model and its effect shave not been fully elucidated. There are discussions especially about action mechanism of technique. Also, some experts state that EMDR is not different from other techniques and can only be complementary to them. In this context, use of EMDR in PTSD treatment is thought-provoking. Is EMDR really an effective method of PTSD's treatment? In the context of this question, this article's purpose is to evaluate there search findings on whether EMDR is appropriate and effective intervention intreatment of PTSD. Regarding the effectiveness of EMDR in PTSD, many studies which in including efficacy and dropout-rates, have been examined. The studies common findings are that EMDR can rapidly cure PTSD and comorbid diagnoses, and recovery can be maintained for a year. In this context, EMDR is thought to be an effective long-term intervention method for PTSD.
\end{abstract}

Keywords: Trauma, stress, EMDR, effectiveness, dropout-rates

Yazışma Adresi: ${ }^{1}$ Alperen Güçlü, Ankara Yıldırım Beyazıt Üniversitesi, İnsan ve Toplum Bilimleri Fakültesi, Psikoloji Bölümü, Esenboğa Merkez Külliyesi Dumlupınar Mah. Küme Evleri No:1/1 A Blok Kat:306760 Çubuk / Ankara, alperenguclu5@gmail.com, ORC-ID: 0000-0003-2737-7193

${ }^{2}$ Prof. Dr., Ankara Yıldırım Beyazıt Üniversitesi, İnsan ve Toplum Bilimleri Fakültesi, Psikoloji Bölümü, Esenboğa Merkez Külliyesi Dumlupınar Mah. Küme Evleri No:1/1 A Blok Kat: 306760 Çubuk / Ankara, ozdenalkar@yahoo.com, ORC-ID: 0000-0001-8484-9199 Gönderim Tarihi: 23.07 .2020

Kabul Tarihi: 08.01.2021 
İnsanlar, hayatları boyunca doğal afet, trafik kazası, savaş, taciz gibi çeşitli olaylarla karşı karşıya kalabilmektedir. Bu tip olaylara maruz kalmak olumsuz ve travmatik bir deneyim olarak kabul edilir. Böyle bir deneyim sonucunda yoğun rahatsızlık hissi, huzursuzluk, aşırı uyarılmışlık hali ve işlevselliğin bozulması şeklinde ilerleyen bir tablo ortaya çıkabilmektedir (Breslau, 2002; Ilic, 2004). Bu tablo, klinik açıdan travmayla ilişkili stres, buna bağlı yaşanan belirtiler de travma sonrası stres semptomlarıdır (İzci ve Ünveren, 2017). İnsanların travmatik stres karşısında gösterdiği belirtilerin bir aydan uzun sürmesi, travma sonrası stres bozukluğu (TSSB) (post traumatic stress disorder [PTSD]) tanısı almasina sebep olmaktadır (Amerikan Psikiyatri Birliği [APA], 2013). TSSB, değinildiği gibi olumsuz bir olaya maruz kalma veya tanıklık etme sonucu olayın yeniden yaşanması, rahatsızlık hissi, biliş ve duygudurum değişiklikleri, uykusuzluk, odaklanma güçlüğü ve uyarılmada artı̧s gibi semptomlarla karakterize bir bozukluktur (APA, 2013). Belirtilerin üç aydan daha fazla sürmesi ise "kronik TSSB" (chronic PTSD) kabul edilmektedir. Bazen de belirtiler hemen değil, olaydan altı ay gibi uzun bir süre sonra ortaya çıkabilir. $\mathrm{Bu}$ durum ise "gecikmeli başlangıçlı TSSB" (Delayed-onset PTSD) olarak adlandırılmaktadır. (APA, 2013).

TSSB, değinildiği gibi travmatik ve örseleyici olaylara bağlı gelișen bir bozukluktur. Travmatik bir durumla karşılaşma yaygınlığı oldukça yüksek olabilmektedir. Örneğin, 18 yaş öncesi bir veya daha fazla travmatik olaya maruz kalma prevalansının ABD ve Avrupa popülasyonu için ortalama \%25-65 arasında değiştiği rapor edilmiştir (Beer, 2018; Kessler ve ark., 2005). Bu açıdan TSSB tanısının da yaygın olduğu düşünülmektedir ancak konuyla ilgili yapılan çalışmalar travmatik bir durumla karşı karşıya kalan herkesin TSSB geliştirmediğini bildirmiştir. Travmatik olaylara maruz kalan kişilerin ortalama \%15-20'sinin TSSB tanısı aldığ ark., 2013; Özçetin, Maraş, Ataoğlu ve İçmeli, 2008). Travmatik olaylarla karşılaşma yaygınlığ temelinde değerlendirildiğinde bu oranın yüksek olduğu belirtilmektedir. TSSB, gerçekten de yaşam boyu görülme yaygınlığ 1 olarak anskiyete bozuklukları (\%33.7) (Bandelow ve Michalis, 2015) ve majör depresyondan (\%16-20) (Hasin ve ark., 2018) sonra ortalama \%8-10 gibi bir oranla en yaygın ruhsal bozukluklardan biridir. Ayrıca "strese bağlı bozukluklar" içinde \%22.7'lik oranla en yaygın stres bozukluğu olduğu da bildirilmiştir (Koenen ve ark., 2017; Piyavhatkul, Paholpak ve Boonpromma, 2018; Reinders, 2019).

Farklı ülke ve popülasyonlarda yapılan çalışmalar TSSB tanısının yaygınlığını destekler niteliktedir. Amerika ve Kanada'da yapılan toplum temelli çalışmalar TSSB yaygınlığının \%4-6 arasında değiștiğini bildirmiştir (Örn., Koenen ve ark., 2017). Wittchen ve arkadaşları (2011) yaptıkları meta analiz çalışmasında Avrupa ülkelerindeki yetişkin popülasyonda TSSB yaygınlığının \%0.6-6 arasında değişebildiğini rapor etmişlerdir. Türkiye bağlamında ise çalışmalar görece daha sınırlıdır. Küçük örneklemlerle yapılan bu çalışmalar \%25-50 (Avc1 ve Doğan, 2014; Önsüz, Topuzoğlu, İkı1şık ve Karavuş, 2009) arası değişen oranlar bildirmiştir. Ayrıca ilgili alanyazında yapılan çalışmalar son 20-30 yıldır TSSB tanısının yaygınlığının iki katına çıktığını da göstermiştir (Reinders, 2019). Reinders, bu sonucun TSSB için tanı ölçüt ve kriterlerinin son yıllarda netleştirilmesi nedeniyle TSSB'li kişilerin daha iyi teşhisi ve insanların akıl sağlığı yardımına daha kolay ulaşabilmesine bağlı olabileceğine değinmiştir. Ayrıca TSSB tanılı kişilerde TSSB'ye ek olarak psikiyatrik bir eş tanı (komorbidite) da yaygın bir durumdur. Özellikle depresif bozukluk, anksiyete bozuklukları, madde kullanım bozukluğu sıklıkla eștanı olarak bulunabilmektedir (Beer, 2018; Breslau, 2002).

TSSB ve eşlik eden bozukluklar özellikle işlevselliği olumsuz yönde etkileyebilmektedir. Günlük hayat, sosyal ve mesleki işlevler, TSSB tanısına bağlı olarak zarar görebilmektedir (APA, 2013). TSSB tanılı bireylerin \%65'e yakınında bozukluk sırasında belirtilerin kötüleşerek şiddetlenebildiği bu durumun da giderek işlevselliği kötü etkilediği rapor edilmiştir (Özgen ve Aydın, 1999). Bazen tanı ile ilgili ikincil kazançların varlığı da (hasta olmanın olumlu yönlerini görme) TSSB'nin gidișatını, dolasıyla da işlevselliği olumsuz yönde etkileyebilmektedir. Bununla birlikte bozukluğun nüks riski de bulunmaktadır. Travmatik olaya ilişkin herhangi bir uyarıcıyla karşılaşma kolayca nükse yol açabilmektedir (Lancaster, Teeters, Gros ve Back, 2016). Ayrıca TSSB'de travmatik bilişler temelinde intihar olasılığı da söz konusudur (Çak1l, 2018). TSSB tanılı kişiler arasında intihar oranının ortalama olarak \%20-27 arasında değiştĭgi rapor edilmiştir (Gradus, 2018; Ramsawh ve ark., 2014).

TSSB'nin yüksek yaygınlığı, sağlığı tehdit etmesi, intihar oranlarının yüksekliği ve ayrıca nüks riskinin bulunması dikkate alındığında tedavisi önem arz eden bir bozukluk olduğu düşünülmektedir. Tanı ilk önerildiğinden bu yana TSSB tedavisi için çeşitli tedavi yöntemleri önerilmiştir. Özellikle, bilişsel davranışçı terapi (BDT), maruziyet terapisi, stres aşılama eğitimi, diyalektik terapi gibi yaklaşımlar en yaygın kullanılanlardır ve etkililiği kanıtlanmış müdahalelerdir (Berg ve ark., 2015; Ironson, Freund, Strauss ve Williams, 2002; Mavranezouli ve ark., 2020). TSSB tedavisindeki güncel müdahalelerden biri de son yıllarda daha popüler hale gelen ve nispeten daha yeni bir teknik olan, Shapiro'nun (1989) geliştirdiği göz hareketleriyle sistematik duyarsızlaştırma ve yeniden işlemedir (eye movement desensitization and reprocessing). Teknik daha yaygın olarak İngilizce yazılımındaki kelimelerin bas harflerinin kısaltılması olan "EMDR" şeklinde de bilinmektedir. 
EMDR'ın TSSB tedavisinde kullanımı son yıllarda giderek hız kazanmıştır ancak EMDR görece yeni bir tekniktir bu yüzden TSSB tedavisindeki diğer yöntemler kadar aydınlatılabilmiş değildir. Özellikle etki mekanizmasına ilişkin tartışmalar mevcuttur. Bu durum EMDR'ın TSSB açısından ne kadar uygun bir müdahale olduğu sorusunu akla getirmektedir. Daha önce de değinildiği gibi EMDR'ın TSSB'deki kullanımı giderek yaygınlaştığından bu sorunun cevaplanması ve TSSB için EMDR kullanımının dikkatlice değerlendirilmesi gerektiği düşünülmektedir. Bunun da ancak Schottenbauer, Glass, Arnkoff, Tendick ve Gray'in (2008) belirttiği gibi tekniğin kullanıldığ 1 popülasyondaki etkililik oranları ve tedavi bırakma oranları temelinde yapılabileceğine inanılmaktadır. EMDR etkililik ve bırakma oranlarının incelenmesinin, TSSB tedavisinin formülasyon ve uygulama sürecine de 1şık tutabileceği düşünülmektedir. Ayrıca bu tarz bir çalışma EMDR ve TSSB ile ilişkili alanyazına da önemli katkılar sağlayabilir. Dolasıyla mevcut derlemede EMDR'ın TSSB'de tedavisindeki uygunluğunun etkililik düzeyi ve tedavi bırakma oranları temelinde çok yönlü ve bütüncül biçimde değerlendirilmesi amaçlanmaktadır.

\section{EMDR ve Travma Sonrası Stres Bozukluğu Göz Hareketleriyle Sistematik Duyarsızlaştırma ve Yeniden İşleme (EMDR)}

Göz hareketleriyle sistematik duyarsızlaştırma ve yeniden işleme (EMDR), Francine Shapiro tarafindan geliştirilmiş, psikodinamik, bilişsel-davranışçı terapi ve varoluşçuluk gibi birçok terapi yaklaşımının çeşitli yönlerini bir araya getiren nispeten yeni bir terapi tekniğidir (Shapiro, 1989, 2002). Diğer terapi tekniklerinden farklı olarak EMDR, ayrıca sakkadik göz hareketlerini de (gözlerin sağa-sola veya aşağı-yukarı hareket ettirilmesi) içermektedir. Shapiro, kişisel deneyimleri sonucu sistematik ve bilinçli olarak yapılan tekrarlı göz hareketlerinin olumsuz bir olayla ilgili var olan rahatsız edici düşüncelerin yoğunluğunu azaltabildiğini fark etmiş ve bu keşfinden hareketle yaptığı erken dönem çalışmalarla EMDR'1 geliştirmiş ve giderek tekniğin içeriğini zenginleştirmiştir (Rubin, 2003; Shapiro, 2002).

Bir tedavi yöntemi olarak EMDR'ın iki temel sayıltısı mevcuttur: Birincisi, patolojik durumlar, bilgi işleme sürecinin ketlenmesi ve anıların sabit, değişmez ve parçalı işlenmesi sonucu oluşur. İkincisi, göz hareketleri gibi çift yönlü bir uyarım, anılarla ilgili olumsuz duyguları ketleyerek işleme sürecini tekrar aktif hale getirebilir ve bu durumda olumsuz olayin etkisi azaltılabilir (Shapiro, 1989, 2002). Bu sayıltılar temelinde EMDR, katılımcıların travmatik bir olay üzerine konuşurken eş zamanlı olarak terapistin parmaklarının sağa-sola veya yukarı-aşağı hareketini (çift yönlü uyarım) izlemesine dayanır. Bu süreç ilerledikçe olumsuz olaya ilişkin anılar işlenmekte ve bellekle bütünleşebilmektedir (Ilic, 2004; Stickgold, 2002). Bu bağlamda EMDR'da temel amaç göz hareketlerini kullanarak olumsuz olaya ilişkin katılımcının duyarsızlaştırılması, anıların normal biçimde işlenmesi ve bu şekilde patolojinin ortadan kaldırılmasıdır (Shapiro, 2002).

EMDR, her biri birbirini izleyen sekiz aşamada uygulanmaktadır. Danışanın öyküsünün alınmasıyla süreç başlar. Daha sonra hazırlık aşamasında teknik hakkında bilgi verilir. Değerlendirme aşamasında, katılımcı hedef anıyı imgeler, buna yönelik olumsuz inançları, ayrıca olumlu bir inanç belirlenir. Duyarsızlaştırma aşamasında katılımcı olumsuz olaya odaklanırken, eş zaman11 olarak terapistin parmak hareketlerini takip edererek uyarılır. Daha sonra yerleştirme aşamasında önceki aşamalarda belirlenen olumlu inancı pekiştirmek için setlere devam edilir. Daha sonra bedenin taranması evresinde somatik kaygı için beden taranır. Son olarak tamamlama (kapanış) evresinde, uzman katılımcıdan geri bildirim alır, rahatlama egzersizleri uygular ve seans sonlandırılır. Tekrar değerlendirme sonraki seansın başında yapılır ve kazanımların korunup korunmadığı değerlendirilir (Shapiro, 1989, 2002).

Araştırmacılar, sekiz aşamalı EMDR uygulamalarının birçok bozukluğun tedavisine kolayca uyarlanabileceğini belirtmektedir. Gerçekten de EMDR günümüzde majör depresyon, kaygı bozuklukları, uyku bozukluklar1, yeme bozuklukları, kişilik bozukluğu (Karadağ, 2020; Wilson ve ark., 2018) ve genellikle de TSSB tedavi sürecinde (Tokgöz, 2018) kullanılan bir terapi tekniğidir. $\mathrm{Bu}$ bağlamda EMDR'ın tanılararası (trans-diagnostic), bütüncül bir psikoterapi olduğu belirtilmektedir (Wilson, ve ark., 2018). EMDR birçok ruhsal bozukluğun tedavi sürecinde kullanılmakla birlikte mevcut derlemede TSSB ve tedavi süreciyle birlikte incelenmesi amaçlanmıştır. Bu bağlamda sonraki bölümlerde tekniğin TSSB tedavisinde kullanımı, etkililiği ve travma anılarına nasıl etki ettiği gibi konulara değinilecektir.

\section{TSSB Tedavisinde EMDR'ın Etkililiği}

EMDR, bugün travma sonrası stres bozukluğu (TSSB) tedavisinde birçok büyük sağlık kuruluşu tarafından onaylanmış ve önerilen (National Institute for Clinical Excellence [NICE], 2005; World Health Organization [WHO], 2013) bir tedavi modeli olmakla birlikte özellikle TSSB için geliştirilmiş bir teknik değildir. Shapiro (1989), EMDR prosedürlerinin olumsuz bir olaya bağlı travmatik stres ve anıların işlenmesini hızlandırabildiği çalışma bulgularından hareketle, EMDR'ın TSSB için etkili bir müdahale olabileceğini önermiştir. $\mathrm{Bu}$ dönemden sonra bu konu üzerine birçok çalışma yürütülmüştür (Örn., Acarturk ve ark., 2016; Karadağ, 2020). Bazı istisnalara karşılık (Örn., Devilly ve Spence, 
1999) çalışmaların ortak bulgusu EMDR'1n ortalama üç seans gibi kısa bir sürede travma semptomlarını iyileştirebildiği ayrıca takip dönemlerinde bir aydan bir yıla kadar travma semptomlarındaki iyileşmenin korunduğu yönündedir (Bal, 2020; Karatzias ve ark., 2019).

Marcus, Marquis ve Sakai (1997) tekniğinin ilk önerildiği dönemlerde etkililiğini değerlendirmek için yaptıkları çalışmada 67 katılımcının \%80'inde travma belirtilerinin azaldığı ve iyileşmenin altı aylık takipte korunduğu rapor etmiştir. Lee ve arkadaşları (2002) benzer şekilde EMDR'la tedavi edilen TSSB tanılı katılımcıların \%85'inde travma semptomları ve eşlik eden depresif semptomların ortadan kalktığını bildirmiştir. Daha sonraki çalışmalarda benzer bulgulara ulaşılmıştır (Örn.,Hutckins ve Clare, 2017). Karatzias ve arkadaşları (2019) yaptıkları çalışmada TSSB tedavisinde EMDR'la tedavi koşulunda \%60-65 gibi bir iyileşme oranı varken, standart tedavi koşulunda bu oranının \%30 olduğunu bulgulamışlardır. De Jongh, Amann, Hoffman, Farrel ve Lee (2019) tarafından yapılan meta analizin sonuçları ilgili alanyazını destekler şekilde TSSB'nin EMDR'la tedavisinde \%60-90 arasında değişen iyileşme oranları bildirmiştir. Lewis, Roberts, Andrews, Starling ve Bisson (2020) 114 randomize kontrollü çalışmayı içeren meta analiz çalışmalarında EMDR'ın TSSB tedavisinde çok kısa sürede etki edebildiği ve oldukça etkili olduğuna ilişkin kanıtlar rapor etmişlerdir. Benzer şekilde yakın tarihli birçok meta analiz ve sistematik derleme çalışmaları EMDR'ın TSSB'de 3-5 seansta iyileşme sağlayabildiğini, komorbit durumların iyileştiğini ve iyileşmenin uzun süre korunduğunu bildirmiştir. (Cuijpers, Van Veen, Sijbrandij, Yoder ve Cristea, 2020; Mavranezolui ve ark., 2020). Ayrıca alanyazındaki bazı meta analiz çalışmaları EMDR' ın yetişkinler kadar çocuk ve ergenlerin TSSB tedavisinde de oldukça etkili olduğunu, komorbit durumları azalttığını ve ortalama 4-12 ay kadar iyileşmenin korunduğunu bildirmiştir (Barron, Bourgaize, Lempertz, Swinden ve Darker-Smith, 2019; Beer, 2018).

Türkçe alanyazında yapılan çalışmalar da yurtd1Ş1 alanyazınını destekler şekilde EMDR'ın TSSB tedavisinde oldukça etkili olabildiğini rapor etmiştir (Bal, 2020; İzci ve Ünveren, 2017). Gürel (2004), yaptığ olgu bildiriminde, trafik kazası sonrası TSSB tanıs1 geliştiren ve iyileşme gösteremeyen bir danışanın 2 seans EMDR sonrasında semptomları üzerine konuşabildiğini, ilerledikçe semptomlarda azalma olduğunu bildirmiştir. Balıbey ve Balıkçı (2013) aynı şekilde ortalama 6 seans EMDR sonrası travma üzerine konuşulabildiğini ve travmanın çözüldügüüü rapor etmiştir. Yurtsever ve arkadaşları (2018) çocuk ve yetişkin mülteciler arasında TSSB semptomları ve depresif belirtilerin tedavisinde EMDR'ın etkililiğini değerlendirdikleri çalışmalarında EMDR sonrası katılımcıların \%60'inda semptomların var olmadığını bildirmişlerdir. Karadag, Gökcek ve Sarp (2019) çocuk ve ergenlerde EMDR'ın etkililiğini değerlendirdikleri çalışmalarında katılımcıların \%53'ünün başta şiddetli TSSB semptomları gösterirken bu oranın EMDR tedavisi sonrası \%13'e düştüğünü bulgulamışlardır. Karadağ (2020) ise 3 seans EMDR grup terapisi sonrası çoklu travma mağduru kadınların Travmatik Stres Envanterinden aldıkları ortalama puanın 53.5'ten 39.40'a düştüğünü, bu bağlamda EMDR'ın etkili bir müdahale olduğunu rapor etmiştir.

Alanyazında EMDR'ın TSSB' de etkililiğini değerlendirebilmek adına EMDR'ı diğer tedavi yöntemleriyle karşılaştıran araştırmalar da mevcuttur (Örn., İzci ve Ünveren, 2017). EMDR etki düzeyi açısından bilişsel davranışçı terapiyle (BDT) sıklıkla karşılaştırılmıştır. Bazı istisnalara karşılık (Örn., Bisson ve ark., 2013), EMDR'ın TSSB şiddetini azaltmada daha etkili olabildiği rapor edilmiştir. Jaberghaderi, Greenwald, Rubin, Zand ve Dolatabadi (2004) travma mağduru kadınlarla çalışırken katılımcıların ortalama ön test-son test puanları açısından EMDR'ın (34.86'dan 18.46'ya düştü) travma belirtilerini iyileştirmede BDT'den (30'dan 22.71'e düştü) daha etkili olabildiğini bildirmişlerdir. Khan ve arkadaşları (2018) yakın zamanda yaptıkları meta analiz çalışmasında EMDR'ın BDT'ye göre daha etkili olduğuna ilișkin kanıtlara ulaşmışlardır. Brannock (2020) benzer şekilde BDT'nin eşlik eden depresyon ve anskiyete semptomlarını daha iyi çözebilmesine karşılık TSSB semptomlarını azaltmada EMDR'ın daha etkili olduğunu bildirmiştir. Buna karşılık EMDR'ın BDT'ye karşı üstünlüğünün mekanizması tam olarak açıklanamamıştır. Yalnızca BDT tedavilerinin yoğun biçimde ev ödevleri gerektirmesinin katılımcıların süreçten faydalanmasını olumsuz biçimde etkileyebileceği ve travma odağının kaçırılabileceği öne sürülmüştür (Moghadam, Kazemi, Taklavi ve Naeim, 2020) ancak daha etkili sonuçlara neyin yol açtığı kesin değildir.

Alanyazında ayrıca maruz bırakma ve EMDR üzerine odaklanan çalışmalar da mevcuttur. Çoğunlukla iki teknik arasında etkililik açısından anlamlı bir fark olmadığ 1 rapor edilmiştir (Örn., Rothbaum, Astin ve Marsteller, 2005) ancak EMDR'ın maruz bırakmaya göre TSSB belirtilerini azaltmada daha etkili olabileceğini destekleyen çalışma bulguları da mevcuttur (Örn., Chen ve ark., 2015). Berg ve arkadaşları (2015), EMDR ve uzatılmış maruz bırakmanın TSSB' deki etkililiğini değerlendirdikleri çalışmalarında iki tekniğin de bekleme listesi kontrol grubuna göre (\%27) daha etkili olduğunu bildirmesine karşılık EMDR'ın maruz bırakmadan daha yüksek iyileşme oranına sahip olabildiğini (\%60'a karşılık \%55) rapor etmişlerdir. Yakın zamanda Stanbury, Drummond, Laugharne, Kullack ve Lee (2020) EMDR'la tedavi edilen katılımcıların maruz bırakmaya göre daha az semp- 
tom şiddeti ve bireysel sıkıntı gösterdiğini bildirmişlerdir. Genel olarak EMDR'ın maruz birakma yöntemine göre daha etkili olabilmesi sonuçları üzerinde maruz b1rakma tipi ve süresinin etkili olabileceği öne sürülmüştür (Örn., Nijdam ve ark., 2012). EMDR'daki aralıklı kısa süreli maruz kalmaya karşılık maruz bırakma tekniğinde maruz kalınan koşulun daha yoğun ve uzun süreli olması ve bunun yarattığı sıkıntının tedavi açısından olumsuz etkileri olabileceği belirtilmiştir.

EMDR'ın TSSB açısından yüksek düzeyde etkili olabildiğini gösteren çalışma bulgularına karşılık alanyazında daha düşük düzeyde iyileşme oranları da rapor edilmiştir (Örn., Jensen, 1994). Devilly ve Spence (1999) EMDR için \%25-30 gibi bir oranla benzer çalışmalara göre oldukça düşük bir etki düzeyi bildirmiştir. Heber, Kellner ve Yehuda (2002) kronik tecavüz mağduru TSSB tanılı katılımcılarla çalışırken EMDR'ın etki düzeyinin düştüğünü, EMDR'ın kronik travma tedavisinde daha az etkili olabileceğini bildirmiştir. Bunu destekler şekilde Van der Kolk ve arkadaşları (2007) yetişkin başlangıçlı TSSB tedavisinde EMDR'ın \%100'e yakın bir etki boyutuna sahipken travmanın çocukluk başlangıçlı biçimde kronik olduğunda etki boyutunun \%65-70 gibi bir orana sahip olduğunu bildirmiştir. Bu ayrımın takip döneminde daha belirgin hale geldiği (\%75'e karşılık \%33.3) rapor edilmiştir. Bu bağlamda araştırmacılar EMDR'ın TSSB semptomlarını iyileştirmede her şekilde etkili olabilmesine karşılık kronik travma gibi bazı faktörlerin EMDR'ın etki düzeyini düşürebileceğini belirtmişlerdir.

\section{Farklı Travma Türlerine Bağlı Gelişen TSSB'de EMDR'ın Etkililiği}

EMDR'in travma sonrası stres bozukluğu (TSSB) tedavisinde etkili olabileceğini gösteren çalışmalardan sonra (Ironson ve ark., 2002; Yurtsever ve ark., 2018) farklı travmatik olaylara bağlı gelişen TSSB'yi iyileştirmede ne kadar etkili olabileceği sorusu gündeme gelmiştir. Bazı araştırmacılar travmatik olayların türü, şiddeti ve kişi için anlamının EMDR'ın etkililiğini değiştirebileceğini belirtse de (Moghadam ve ark., 2020), EMDR'ın travma anıları üzerinde oldukça etkili olabildiğini gösteren çalışmalara bağlı olarak travma türü fark etmeksizin benzer etki düzeyleri olabileceğine değinen uzmanlar da mevcuttur (Wagenmans, Van Minnen, Sleijpen ve De Jongh, 2018). Bu açıdan bu bölümde üç farklı travmatik olaya bağlı gelişen TSSB'de EMDR etkililik oranları incelenecektir.

Doğal afet. Çalışmaların ortak bulgusu doğal afet mağdurlarının \%15-20'sinin TSSB geliştirdiği ve bu oranın \%35'e kadar çıkabildiğidir (Trentini ve ark., 2018). Oranların yüksekliği bağlamında değerlendirildiğinde TSSB tedavisi önemli görünmektedir. Pek çok çalışma doğal afet ilişkili travma tedavisi için EMDR kullanımı- nı desteklemektedir. EMDR, erken dönem bir çalışmada Andrews kasırgası mağdurlarında kullanılmış ve felaketi izleyen iki ay sonra, tek seans EMDR sonras1 \%60 oranında iyileşme oranları olduğu rapor edilmiştir (Grainger, Levin, Allen-Byrd, Doctor ve Lee, 1997). Ichii (1997), Hanşin depreminden kurtulan 18 TSSB tanılı katılımcıyla çalışırken EMDR uygulamıştır. Tedavi sonucunda TSSB belirtilerinin azaldığı, "artçı depremlere" rağmen takip sürecinde iyileşmenin \%80 oranında korunduğu rapor edilmiştir. Abbasnejad, Mahani ve Zamyad (2007), farklı olarak doğal afet mağdurlarıyla çalışırken grup prosedürü şeklinde EMDR'1 kullanmışlardır. EMDRgrup prosedür sonrası dahi katılımcıların travmaya ilişkin belirtilerinin azaldığ 1 ve aylık izlemlerde iyileşmenin devam ettiği rapor edilmiştir. Benzer olaylar yaşayan kişilerle birlikte olmanın EMDR'ın etkililiğini desteklemiş olabileceği varsayılmıştır. Türkiye'de yakın zamanda benzer çalışma bulgularına ulaşılmıştır. Konuk ve arkadaşları (2006) Marmara depremi sonrası TSSB tanılı katılımcılarla çalışırken iki seans EMDR sonrası travma belirtilerinin azaldı ̆̆ını ve altı ay iyileşmenin korunduğunu bildirmişlerdir. Mukba, Tanrıverdi ve Tanhan (2020), Van depremi sonrası uzun süreli TSSB semptomları gösteren bir katılımcının ortalama 7 seans EMDR sonrası TSSB ölçeğindeki tekrarlayan düşünceler (25'e karşılık 10) fizyolojik uyarılma (32'ye karşılık 15) ve zihinsel kaçınma (32'ye karşılık 16) alt ölçeklerindeki ön-test ve son-test puanları arasında farklılıklar olduğunu ve TSSB semptomlarının kısa sürede iyileştiğini rapor etmişlerdir.

Cinsel taciz. Çalışmaların ortak bulgusu cinsel tacizin en yıkıcı travmatik olayların başında geldiği ve mağdurların \%30-40'1nda TSSB görülebildiğidir (Binay, 2016). Bu oranlar TSSB tedavisinin önemine işaret etmektedir. Pek çok çalışma cinsel taciz sonucu TSSB tedavisi için EMDR'ın kullanımını desteklemektedir. Rothaum (1997), taciz mağdurlarında EMDR'ın etkisini araştırmış, EMDR alan ve almayan grupları kıyaslamıştır. EMDR tedavisi alan katılımc1ların \%90'ında travma belirtilerinin azaldığ 1 ve iyileşmenin aylar sonra dahi korunduğu rapor edilmiştir. Edmond ve Rubin (2003), cinsel travma mağduru 59 kadınla yaptıkları çalışma sonucu EMDR'ın standart tedaviye oranla daha fazla çözülme duygusu sağladığını, cinsel travma belirtileri ve depresif belirtilerin azaldığını bildirmiştir. Hutchins ve Clare (2017), erkeklerde tacize bağlı TSSB'de EMDR'ın etkililiğini değerlendirmek için yaptıkları çalışmada erkek katılımcının yedi seans EMDR sonrasında TSSB tanısından tamamen kurtulduğu bildirmiştir. Türkiye' de benzer çalışma bulgularına ulaşılmıştır. Sinici, Maden, Ak, Bozkurt ve Özşahin (2012), taciz mağduru TSSB tanılı bir danışanla çalışırken EMDR kullanmış ve danışanın TSSB belirtilerinde belirgin bir düşüş olduğunu (\%5060 ), eşlik eden bozuklukların şiddetinin azaldığını ve bir 
aylık izlemde iyileşmenin korunduğu rapor etmişlerdir. Karadag ve arkadaşları (2019) cinsel taciz mağduru kat1lımcılarla çalışırken TSSB semptom skorları arasında istatistiksel olarak anlamlı bir fark olduğunu (60' dan 24'e düştü) bildirmiştir. Karadağ (2020) benzer şekilde taciz mağduru ergen kızlarla çalışırken 3 seans EMDR grup terapisi sonrası katılımcıların travma ölçeğinden aldıklar1 ortalama puanın 53.5'ten 39.40'a düştüğünü ve TSSB ve eşlik eden semptomların iyileştiğini rapor etmiştir.

Savaş. Çalışmalara göre savaşlardan sağlam veya gazi olarak dönen askerlerde ve savaşın yıkıcı etkilerine maruz kalan kişilerde TSSB geliştirme oranı ortalama olarak \%45-50 arasındadır (Sagaltici, Alpak ve Altindag, 2019). Oranların yüksekliği göz önüne alındığında TSSB'nin tedavisi önemlidir. Pek çok çalışma savaş sonrası TSSB tedavisi için EMDR kullanımını desteklemektedir. Russell (2008), Irak savaşında savaşmış ve TSSB tanı kriterlerini karşılayan 67 kişiyle çalışırken EMDR'1 kullanmıştır. Russell, tedavi edilen askerlerin sadece bir seanstan sonra savaş üzerine konuşmaya başladıklarını ve üç seans sonra semptomların ortadan kalktığını rapor etmiştir. Hurley (2018), Vietnam gazileri üzerinde EMDR'ın etkililiğini değerlendirmek için katılımcıların yarısına hafta boyunca günde iki seans EMDR uygularken diğer yarısına haftada bir 90 dakikalık EMDR seansı uygulamıștır. Çalıșma sonunda her koșulda EMDR'ın TSBB belirtilerini ortalama \%80 oranında iyileştirdiği ve iyileşmenin korunduğu rapor edilmiştir. Ayrıca kayıp ve yasa yönelik belirtilerin de iyileştiği bildirilmiştir. Köhler ve arkadaşları (2017) ise, EMDR'ın TSSB'li askerlerde kullanımı konusunda görece zayıf bir etki rapor etmişlerdir. Savaşların yıkıcı etkisinin oldukça büyük olabildiğini öne sürerek EMDR'ın bu grupta etkili olabileceğini ancak diğer tekniklerle tamamlanması gerektiğini önermişlerdir. Bilindiği kadarıyla ülkemizde doğrudan askerler üzerine yapılan bir çalışma bulunmamaktadır. Buna karşılık iç savaştan kaçarak Türkiye'ye sığınan mültecilerle yapılan çalışmalar EMDR'ın savaşın travmatik etkilerine karşı olumlu sonuçlar gösterebileceğini rapor etmiştir. Örneğin Acarturk ve arkadaşları (2015) mültecilerle çalışırken EMDR terapisi sonrası katılımcıların Travma Ölçeğindeki ön test-son test puanları arasında anlamlı farklılıklar (64.30'a karşılık 22.20) olduğunu bildirmiştir.

\section{EMDR'ın Etki Mekanizması:}

\section{İyileşme Nasıl Gerçekleșiyor?}

EMDR'ın, travma sonrası stres bozukluğu (TSSB) tedavisinde etkililiğini destekler çalışma bulgularına karşılık EMDR'ın travma belirtilerini nasıl azalttığı ilgili alanyazında sıklıkla tartışılan bir konudur. Tekniğin etki mekanizması henüz aydınlatılabilmiş değildir (İzci ve Ünveren, 2017). Shapiro (1989) konuya ilişkin ola- rak "Uyumsal İşleme Modelini”" önermiştir. Bu modele göre travmatik bir anı doğası gereği olumsuz olduğundan bilgi işleme sistemi tarafından işlenememektedir ve bu durum patolojiye yol açmaktadır. Ancak sakkadik göz hareketleri gibi bir uyarımının kullanılması sistemi harekete geçirerek anıların işlenebilmesini sağlamakta ve böylece travma anıları iyileşebilmektedir. Shapiro'nun önerisine karşılık sonradan bu modelin etki mekanizmasından ziyade EMDR'a kuramsal bir temel sağladığı, değişime aracılık eden faktörler açısından sınırlı olduğu belirtilmiştir (Tokgöz, 2018). Bundan dolayı birçok araştırmacı EMDR'ın etki mekanizmasına ilişkin önerilerde bulunmuştur.

Andrade, Kavanagh, Baddeley (1997), EMDR'da travmatik görüntülerin canlılığı ve travma deneyiminin etkisinin, çalışma belleğinin görsel bilgileri tutan ve tekrarlayan görsel-uzamsal kopyalama bölümünün (visuospatial sketchpad) faaliyetleri aracılığıyla azaldığını ileri sürmüştür. $\mathrm{Bu}$ görüşe göre EMDR seansı sırasında katılımcıların travma anılarına odaklanırken ritmik hareketleri takip etmesi, çalışma belleğinin sınırlı kapasitesini iki yoğun işlem arasında bölmesine neden olmaktadır. $\mathrm{Bu}$ şekilde tekrarlı görsel uyarım sonucu travmatik olaya ilişkin anılara daha az kapasite kalmaktadır. Travmatik olaya ve anılara yeterince odaklanılamadığından dolayı da göz hareketleriyle uyarılmaya devam edildikçe anılar canlıl1ğını yitirmekte ve böylece iyileşme sağlanmaktadır.

Stickgold (2002), EMDR'ın TSSB belirtilerini azaltmadaki etkililiğini uyku fizyolojisi ve REM uykusu sırasındaki sakkadik göz hareketlerini temel alarak açıklamıştır. Stickgold'a göre EMDR uygulaması sırasındaki çift yönlü uyarım, REM uykusu sırasındaki göz hereketleriyle benzer işlev görmektedir. EMDR' daki çift yönlü uyarıma tekrarlı bir biçimde odaklanma bir tepki zincirine yol açmaktadır. Çift yönlü uyarımlar giderek beyin sapının ilgili bölgeler için REM benzeri aktivasyon başlatmasına yardımcı olmaktadır. Bu aktivasyon süreci de travmaya ilişkin epizodik anıların kortikal bir biçimde semantik (anlamsal) belleğe entegre olmasını hızlandırarak rahatsız edici anıların işlenmesini kolaylaştırmaktadır. Tüm bu işlemleme süreci sonunda ise TSSB belirtileri ortadan kalkmaktadır.

Bergman'a (2008) göre olumsuz olaya ilişkin travma belleği, beynin sağ yarım küresinde yer almakta ve bu bellek sağ yarım küre ile sol yarım küre arasındaki iletişimi engelleyerek travmatik olay ve olayın yarattığı etki üzerine konuşmayı zorlaştırmaktadır. Bu şekilde anıların işlenmesi de olumsuz yönde etkilenebilmektedir. Bergman, EMDR'da kullanılan iki yönlü uyarımın sağ yarım küreyi harekete geçirerek hemisferler arası iletişimi ve travma anılarının sol yarım küredeki ifade merkezleriyle bütünleşmesini sağlayabildiğini belirtmiștir. Ona göre hemisferler arasında kurulan bağ bellek bütünleşmesine 
yol açmaktadır ve bu şekilde travmatik anılar üzerine konuşulabilmesiyle de travma çözülebilmektedir.

EMDR'ın travmatik anıların çözülmesindeki etki mekanizmasına ilişkin birçok açıklama mevcut olmasına karşılık bu konuda bir fikir birliği bulunmamaktadır. Yalnızca göz hareketleri gibi çift yönlü bir uyarımın travma anılarının çözülmesi açısından oldukça önemli olduğu vurgulanmıştır (Shapiro, 2002). Bazı araştırmacılar teknik ilk önerildiğinde EMDR'da göz hareketleri olmadan da anıların çözülebileceğini önerseler de (Örn., Cahill, Carrigan ve Freuh, 1999) son zamanlarda birçok randomize kontrollü çalışmayı içerecek şekilde yapılan meta analiz ve sistematik gözden geçirme çalışmaları göz hareketlerinin travmatik anıları daha az canlı hale getirmeye hizmet edebildiğini ve bu şekilde anıların kolay bir biçimde işlenebildiğine ilişkin kanıt sağlamıştır (Bal, 2020; Cuijpers ve ark., 2020).

\section{TSSB Tedavisinde EMDR Bırakma Oranları}

Bırakma oranları bir tekniğin kullanımı, kullanıldığı popülasyondaki uygunluğu ve dolaylı olarak etkililiğini belirleyebilecek önemli bir faktördür (Stansbury ve ark., 2020). Bırakma (dropout), klinik açıdan "bir bozukluğun tedavisi sırasında tedavinin beklenenden önce sonlandırılması" olarak tanımlanmaktadır (Acarturk ve ark., 2016, s.2585). Diğer bir deyişle süreç sonlanmadan tedavinin bırakılmasına karşılık gelmektedir. Alanyazında TSSB için bırakma oranının ortalama \%25 civarı olduğu rapor edilmiştir (Bradley, Greene, Russ, Dutra ve Westen, 2005). Reinders (2019) tarafindan 25 randomize kontrollü çalışmanın dahil edildiği meta-analiz çalışmas1 ise tedaviler arası bırakma oranının \%31.97 olduğunu bildirmiştir. Oranların yüksekliği temelinde TSBB tedavisinde etkililiği kanıtlanan EMDR'da bırakma oranlarının ne düzeyde olduğu sorusu akla gelmektedir. Bu durumun değerlendirilmesi tedavi süreci açısından önemli görünmektedir. Bu bağlamda bu bölümde TSSB tedavi sürecinde katılımcıların EMDR tedavisini bırakma oranlar1 ve bu durumun olası sebepleri incelenecektir.

Erken dönem yapılan çalışmalarda EMDR için ortalama $\% 10$ ile $\% 15$ arasında değişen bırakma oranları bildirilmiştir (Ironson ve ark., 2002; Marcus ve ark., 1997). Daha sonraki yapılan çalışmalar da erken dönem çalışma sonuçlarını destekler niteliktedir (Van den Berg ve ark., 2015). Hurley (2018) gazilerle çalışırken yalnızca \%14 gibi düşük düzeyde bir bırakma oranı rapor etmiştir. Türkçe alanyazında yapılan çalışmalar görece daha sınırlı olmakla birlikte yurtdışı alanyazını destekler niteliktedir. Acarturk ve arkadaşları (2016) Suriyeli mültecilerle yaptıkları çalışmalarında EMDR için \%12 gibi bir bırakma oranı bildirmiştir. Benzer şekilde Karadag ve arkadaşları (2019) TSSB tedavisinde EMDR için \%9-10 gibi oldukça düşük bir bırakma oranı rapor etmiştir. Buna karşılık daha sınırlı olmakla birlikte tedavi için bırakma oranlarının \%15'ten daha yüksek olabildiğini bildiren çalışmalar da mevcuttur. Örneğin, Slotema, Van den Berg, Driessen, Wilhelmus ve Franken (2019) TSSB'ye ağır bir patoloji eşlik ettiğinde bırakma oranlarının \%35 gibi oranlarla daha yüksek düzeyde olabildiğini rapor etmiştir. Van der Kolk ve arkadaşları (2007) ayrıca travmanın çocukluk başlangıçlı ve kronik olduğu takdirde bırakma oranlarının yükseldiğini bildirmişlerdir.

Araştırmacılara göre EMDR'da bırakma oranlar1nın tek başına değerlendirdiği çalışmalar değerli olmakla birlikte bir tekniğin bırakma oranları ancak kullanılan diğer tekniklerle karşılaştırılarak anlaşılabilir (Najavits, 2015). Power ve arkadaşları (2002), TSSB tanılı yüz beş katılımcıyla çalışmış ve katılımcıların bir kısmı EMDR bir kısmı maruz bırakma koşuluna atanmıştır. Çalışma sonunda maruz birakma koşulunda, EMDR'a göre b1rakma oranının daha yüksek olduğu (\%16'ya karş1 \%10) bildirilmiştir. Ironson ve arkadaşları (2002) TSSB tanılı katılımcılara EMDR ve maruziyet temelli BDT tedavisi uygulamışlar ve çalışma sonunda bırakma oranlarında anlamlı farklar elde etmişlerdir. On ikişer katılımcının atandığı koşullardan EMDR'da bir kişinin, BDT'de ise altı kişinin tedaviden ayrıldığ 1 bildirilmiştir. Buna karş1lık başka bir çalışmada Berg ve arkadaşları (2015) maruz birakma (\%24.5) ile EMDR (\%24.3) tedavisindeki bırakma oranları arasında anlamlı bir fark bulamamıştır. Jaberghaderi ve arkadaşlarının (2004) yaptığı başka bir çalışmada ise bilişsel davranışçı terapi ve EMDR tedavisindeki bırakma oranlarının yaklaşık olarak aynı olduğu rapor edilmiş, bu açıdan bırakma oranları açısından tedaviler arasında fark olmayabileceği belirtilmiştir.

TSSB' nin EMDR ile tedavisinde birakma oranlar1nı inceleyen araştırma bulguları farklılık gösterebilse de bildirilen ortak sonuç bırakma girişimlerinin EMDR'da çoğunlukla düşük düzeyde olduğudur (Örn., Reinders, 2019). Bu açıdan araştırmacılar EMDR tekniğinde bırakma oranlarının niçin daha düşük düzeyde olduğunu konusunda bazı varsayımlarda bulunmuşlardır. Genel olarak EMDR'daki bırakma oranlarının düşüklüğü, EMDR'ın tedaviyi alan katılımcılar tarafindan avantajlı görülerek daha kolay bir biçimde tolere edilebildiği görüşüyle açıklanmaya çalışılmıştır (Karadag ve ark., 2019; Najavits, 2015). Araştırmacılar bu konuda EMDR'ın daha az maliyetli olması, hızlı etki edebilmesi, maruz bırakma koşullarının görece daha az yoğunlukta olması gibi sebeplerin tedavinin tolere edilebilirliğini, dolasıyla da bırakma oranlarının düşüklüğünü yordayabileceğini savunmuşlardır.

Shapiro'ya (2002) göre EMDR' da yoğun maruz b1rakma müdahalelerinin bulunmayışı olayla yüzleşmekten korkan katılımcılar için kolay görülmekte bundan dolay1 da bırakma oranları daha düşük olabilmektedir. Bunu destekler şekilde Schnyder (2005) travmatik deneyimden 
rahatsız olan kişilerde yoğun maruziyetin yeniden travmatizasyona neden olabileceğini bundan dolayı tedavinin yarıda kesilebileceğini, buna karşılık EMDR'da maruz bırakmanın yoğunluğunun daha az olmasına bağlı olarak bırakma oranlarının düşük olabileceğini savunmuştur. Lancaster, Dodd ve Williamson (2004) ise tedavisi süren katılımcılarla yaptıkları görüşmeler sonucunda katılımcıların EMDR'ın yönetilmeyecek kadar yüksek bir sıkıntıya yol açmadığına inandıklarını rapor etmiştir. $\mathrm{Bu}$ açıdan katılımcıların güvenlik algılarının bırakma oranlarının düşüklüğünü yordayabileceği varsayılmıştır.

Marcus ve arkadaşları (1997), TSSB tedavisinde EMDR'la henüz üç seans sonrasında belirtilerin şiddetinde yarı yarıya bir düşme olduğunu belirledikleri çalışma bulguları temelinde EMDR'ın kısa süreli ve hızlı etki eden bir terapi olmasından dolayı TSSB tanılı kişiler tarafindan daha kolay tolere ediliyor olabileceğini belirtmiştir. Lee ve arkadaşları (2002) TSSB üzerine yaptıkları çalışmalarında EMDR'la tedavi edilen koşulda daha hızlı iyileşme olduğunu ayrıca en düşük bırakma oranlarının da yine EMDR seansında olduğunu belirlemiștir. Buradan hareketle tekniğin hızlı sonuç vermesinin devam etme kararını yordayabileceğini bildirmişlerdir. Karadag ve arkadaşları (2019) da benzer şekilde bırakma oranlarının düşük olması üzerinde EMDR'ın daha kısa süreli olması bakımından TSSB tanılı katılımcılar tarafından daha avantajlı görülmesinin etkili olabileceğini belirtmişlerdir.

Russell ve Figley (2013), EMDR'1 konu alan kitaplarında EMDR'ın TSSB tedavisinde kullanılan diğer davranışsal-bilişsel teknikler gibi haftada kırk-elli saatlik ödevler içermemesinin büyük bir avantaj olduğunu belirtmiştir. Günlük ve haftalık ev ödevlerinin tedavi açısından yararlı görülmesine karş1l1k yoğunluk oluşturduğu ve büyük bir iş yükü gerektirdiğini ifade ederek EMDR'ın böyle bir yükümlülük gerektirmemesi ve müdahalelerin seanslarla sınırlı olmasının tedaviye devamı ve bırakma oranlarının düşüklüğünü etkiliyor olabileceğini belirtmişlerdir. Benzer şekilde Moghadam ve arkadaşları (2020) da ev ödevleri içermemesinin EMDR tekniğinin önemli bir artısı olabileceğini vurgulamışlardır.

De Bont ve arkadaşları (2019) bırakma oranlarını değerlendirirken güvenlik algısı, hızlı etki veya ödevlerden farklı bir noktaya değinmiş ve maliyet üzerinde çalışmışlardır. Araştırmacılar çalışmaları kapsamında TSSB tanılı bireylerle çalışırken standart tedaviye EMDR tedavisinin eklenmesinin, BDT'yi eklemekten daha yüksek düzeyde tasarruf sağladığını belirlemişlerdir (neredeyse yarı yarıya). Bu açıdan TSSB tedavisi sırasında bırakma oranlarının düşük olması üzerinde tekniğin maliyetinin düşük olmasının da etkili olabileceğini ifade etmişlerdir. Ayrıca maliyetin düşük olmasının güvenlik algılarından sonra bırakma oranlarının düşüklüğünü yordayan en önemli faktör olabileceğini de savunmuşlardır.

\section{Tartıșma ve Sonuç}

Travma sonrası stres bozukluğu (TSSB), travmatik bir deneyim sonucu kişilerin hayatlarını çeşitli yönlerden olumsuz etkileyebilen bir bozukluktur. Özellikle işlevselliği düşürmesi, yoğun duygusal sıkıntıya yol açması ve nüks riskinin bulunması gibi sebeplerden dolay1 TSSB tedavisi önemlidir. EMDR, TSSB tedavisinde son yıllarda kullanılan ve popülerliği giderek artan bir müdahaledir ancak EMDR'ın yeni bir teknik oluşu ayrıca teknik ve etki mekanizması konusundaki tartışmalar EMDR'ın TSSB için uygun bir müdahale olup olmadığını düşündürmektir. Bu açıdan bu yazıda TSSB tedavisinde EMDR uygulamalarının etkililiğinin çeşitli yönlerden bütüncül olarak değerlendirilmesi amaçlanmıştır.

Alanyazında EMDR'ın TSSB tedavisinde etkililiğine yönelik çalışma bulguları, EMDR'ın travma sonrası stres deneyimini iyileştirmede etkili olabileceğini göstermiştir (Örn., Acarturk ve ark., 2016; Bal, 2020; Stanbury ve ark., 2020). Çalışmaların ortak bulgusu, EMDR'ın TSSB belirtilerini ortadan kaldırabildiği, depresif belirtileri azaltabildiği ve işlevselliği hızlı bir biçimde arttırdiğ1 şeklindedir (Chen ve ark., 2015; Karadağ, 2020). EMDR' 1n TSSB belirtilerini iyileştirmekle birlikte diğer belirtilere de etki etmesi ve işlevselliği büyük oranda düzeltmesi tekniğin TSSB'de kullanımını destekler niteliktedir. İlgili alanyazında TSSB tanısının işlevselliği düşürdüğü ve yaşanan duygusal sıkıntının depresyon ve kaygı bozukluklarına yol açabildiği belirtilmektedir (Karadağ, 2020). Bu açıdan EMDR'ın travma belirtilerinin yanında diğer belirtileri de azaltarak çok yönlü bir değişime imkan verdiği ve "bir taşla iki kuş vurmayı" sağladığına inanılmaktadır.

EMDR'ın TSSB'de etkilli olabileceğine ilişkin kabule karşın EMDR'ın etki mekanizması aydınlatılabilmiş değildir. Bu durumun aslında göz hareketlerinin temel mantığının ve işlevinin anlaşılamamış olmasından kaynaklanması olasıdır. Araştırmacılar, EMDR'ın travmayı nasıl iyileştirdiğine ilişkin farklı görüşler ortaya koymuştur (Andrade ve ark., 1997). Farklı odak noktalarına rağmen ortak görüş göz hareketlerinin beyni uyarmaya hizmet ettiği, bir dizi tepkisel olaya yol açtığ 1 ve bu şekilde beyinde travma anılarının işlenebileceği bir sistemin harekete geçtiğidir (Örn., Bal, 2020; Rubin, 2003). Bu açıklamalar tekniğin nasıl çalıştığını göstermesi adına değerli görünmektedir ancak etki mekanizması konusunda bir fikir birliği bulunmamaktadır. Göz hareketlerinin etkisi olduğu gösterilmekle birlikte bu durum açık değildir. Göz hareketlerinin birden fazla işlevi olması ve farklı yönlerden etki edebiliyor olması da olasıdır. Bu durumun aydınlatılmasının tekniğin TSSB'de kullanımı açısından faydalı olacağına inanılmaktadır. Araştırmacıların nörobiyolojik açıklamaları temelinde, 
beyin görüntüleme ve ilgili araştırmalardaki artışın bu konuda yararlı olabileceği düşünülmektedir.

Göz hareketlerinin tekniğin kullanımında önemli olduğunu gösteren çalışma bulgularına karşılık bununla çelişen bazı bulgular da mevcuttur. Bazı araştırmacılar göz hareketleri olmaksızın da anıların işlenebildiği rapor etmiştir (Örn., Cahill ve ark., 1999). Bu açıdan çalışma bulguları karmaşık görünmektedir. EMDR'a özgü olan ve tekniğe ismini veren göz hareketlerinin herhangi bir fark oluşturmaması diğer yöntemlerden ayrılan bir yönü olup olmadığı konusunda düşündürücüdür. Davidson ve Parker (2002), bununla ilgili eğer göz hareketlerinin bir etkisi yoksa geriye kalanın olumsuz düşüncelerin işlenmesi yani BDT'den farklı bir şey olmadığını öne sürmüştür. Buna karşılık Van den Hout ve arkadaşlar1 (2010) tarafından yapılan yakın tarihli bir çalışmada göz hareketlerinin bulunduğu ve bulunmadığı koşullar, göz hareketleri yerine geçen "bip sesleri" gibi uyarımlar kıyaslanmış ve bu çalışma sonucunda her koşulda göz hareketleri kullanımının anıları daha az canlı hale getirmeye hizmet ettiği bildirilmiştir. Bu açıdan bulgular tartışmalıdır ve bazı sorulara açık bir cevap verilebilmiş değildir. Konuyla ilgili daha fazla çalışmaya ihtiyaç duyulduğuna inanılmaktadır.

Etki mekanizmasının aydınlatılamamış olmasına karşın EMDR, travma tedavisinde etkili olabilecek bir müdahale olarak kabul edilmektedir. Tedavi sonras1 izlem çalışmaları da EMDR'ın etkililiğini destekler nitelikte görünmektedir. Alanyazında EMDR'la tedavi edilen katılımc1larda tedaviden sonra 12 aya kadar iyileşmenin korunabildiği rapor edilmiştir (Örn., Barron ve ark., 2019; Yurtsever ve ark., 2018). TSBB'de travmatik olayın hatırlatıcılarının kolayca nükse yol açabileceği düşünüldüğünde EMDR'ın nükse yönelik başarısı TSSB tedavisinde kullanımına ilişkin bir destek olarak düşünülebilir ancak bazı çalışmalar EMDR'la tedavi edilen her travma mağdurunun tamamen iyileşmediğini, belirtilerin devam edebildiğini rapor etmiştir (Wise, Zierlier, Kriger ve Harlow, 2001). Benzer travmatik olaylar yaşamalarına karşın bazı kişilerin tamamen iyileşirken diğerlerinin niçin nüks ettiği açık değildir. Alanyazında doğrudan EMDR'la tedavi sonrası nüks üzerine odaklanan çalışmalar olmadığ 1 görülmüştür. EMDR'ın TSSB tedavisinde uygulanabilirliğinin daha iyi anlaşılması için nüks süreçlerinin ve nüksü yordayan değişkenlerin ele alınması fayda sağlayabilir.

EMDR'ın olumsuz anıları işleyerek travmayı çözebileceği görüşünden (Shapiro, 1989) hareketle farklı travmatik olaylara bağlı gelişen TSSB'de etkili olabileceği düşünülmüştür. Bundan dolayı yazı kapsamına doğal afet, savaş, cinsel taciz gibi olaylara bağlı TSSB'de EMDR kullanımına ilişkin çalışma bulguları dahil edilmiştir. Çalışmalar, EMDR'ın farklı olaylara bağlı TSBB'de et- kili olabildiğini, kısa sürede travmaya ilişkin belirtilerin azaldığını ve ortalama benzer iyileşme oranları olduğunu rapor etmiştir (Örn., Hutchins ve Clare, 2017; Mukba ve ark., 2020). Buna karş1lık Köhler ve arkadaşları (2017), savaş mağdurlarında EMDR'ın etkili ancak yeterli bir müdahale olmayabileceğini bildirmiştir. Bu konuya ilișkin karmaşık bulgular söz konusudur. Genel olarak belli bir etki olduğu açıktır ancak EMDR'ın hangi tip olaylarda daha etkili olduğu net değildir. Bu ancak bütüncül biçimde farklı olaylara bağlı TSSB geliştirmiş katılımcılarla çalışılması sonucu anlaşılabilir ancak alanyazında bu tür çalışmaların sınırlı olduğu görülmüştür. Farklı travma mağdurları ile çalışılmasının EMDR'ın etki düzeyleri ve hangi travmatik olayların tedavisinde daha etkili olabileceğine dair fikir verebileceği ve formülasyon ve tedavi sürecine de rehberlik sağlayabileceğine inanılmaktadır.

EMDR'ın uygulanabilirliğini destekler nitelikteki çalışma bulgularına karşın bir müdahalenin herhangi bir bozukluğun tedavisinde kullanımı için etkililik (effectiveness) çalışmaları önemli olmakla birlikte etkinliğe (efficacy) yönelik çalışmalar da değerli bilgiler sağlayabilmektedir. Psikoterapi açısından "kullanılan psikoterapi yaklaşımının kontrollü şekilde uygulandığında yarar sağlama becerisi" olarak tanımlanan etkinlik (Andrews, 1999, s.318) ve "terapide kullanılan yaklaşımın çalışmada uygulandığ haliyle ürettiği etki” olarak tanımlanan etkililik (Andrews, 1999, s.317) kavramları çoğunlukla birbirinin yerine kullanılmakla birlikte aralarında ufak farklılıklar vardır. Ancak her ikisi de bir tekniğin güvenirliği ve uygulanabilirliğinin bir ölçütüdür. $\mathrm{Bu}$ açıdan aslında iki tip çalışmanın birlikte ele alınmasının tedavinin kullanımı açısından önemli olduğuna inanılmaktadır ancak alanyazında buna yönelik çalışmaların sınırlı olduğu, etkililik ve etkinlik çalışmalarına ayrı odaklanıldığ1 görülmüştür (Hurley, 2018; Yurtsever ve ark., 2018). İki tür çalışma sonuçları da EMDR'ın TSSB'de değişim sağladığını bildirmiştir. En küçük etki boyutunu gösteren Devilly ve Spence'in (1999) çalışması dahi belirli bir etki rapor etmiştir. Bu sonuçların EMDR'ın etkili bir müdahale olabileceğini göstermesi açısından değerli olduğu düşünülmektedir. Bununla birlikte TSBB'de EMDR çalışırken etkinlik ve etkililiğe birlikte daha fazla odaklanılması tekniğin kullanımı ve uygunluğu açısından destekleyici olabilir.

EMDR' 'n TSSB tedavisinde kullanımı ve uygunluğuna ilişkin bir ölçüt olarak derleme kapsamına bırakma oranları dahil edilmiştir. Genel olarak çalışmaların ortak bulgusu, EMDR bırakma oranlarının diğer yöntemlere kıyasla düşük (ortalama \%15) olduğudur (Acarturk ve ark., 2016; Reinders, 2019). Araştırmacilar bu sonucu EMDR'ın daha kolay tolere ediliyor olabileceği görüşüyle açıklamışlardır (Örn,, Karadag ve ark., 2019). Yani aslında tedaviye devam kararını etkileyen faktörler 
üzerinden dolaylı biçimde bırakma oranlarına değinilmiştir. İlgili alanyazında EMDR tedavisini bırakmanın yordayıcılarına odaklanan çalışmalara rastlanmamıştır. Schottenbauer ve arkadaşları (2008), EMDR'de bırakma ve tepkisizliği yordayan değişkenler üzerine bir çalışma olmamasına değinmiştir. Yakın tarihte Lewis, Roberts, Gibson ve Bisson (2020) da EMDR çalışmalarında tedaviyi erken sonlandırma sebeplerine yer verilmediğini belirterek bunu eleştirmiştir. EMDR'ın bırakma oranlarının genellikle düşük olması açısından devam kararına neyin yol açtığını değerlendirmek mantıklı görünse de düşük de olsa bir bırakma oranı söz konusudur ki bazı çalışmalar \%15'in üzeri oranlar da bildirmiştir (Örn., Nijdam ve ark., 2012). Bu açıdan bu durumun yordayıcılarının incelenmemesinin bir sınırlılık olduğu düşünülmektedir. EMDR'la tedavide tedaviyi bırakma kararının yordayıc1ları üzerine odaklanılması tekniğin kullanımı ve uygunluğu açısından önemli olabilir.

Mevcut derlemede EMDR'in TSSB'de kullanımına ilişkin farklı yönlerin klasik çalışmalar ve güncel bulgular temelinde bir araya getirilmesi ve farklı travma türleri sonucu gelişen TSSB' de EMDR kullanımı ve etkililiğine yer verilmesinin derlemenin güçlü yönünü oluşturduğu düşünülmektedir. Ayrıca Türkiye'de etkililik düzeylerine değinilmekle birlikte bırakma oranlarına fazla yer verilmediği görülmüştür. Bu açıdan derlemenin sınırlı alanyazına da katkı sağlayacağına inanılmaktadır ancak derlemenin bazı sınırlılıkları da mevcuttur. Öncelikle bu derlemenin yalnızca TSSB tedavisinde EMDR'ı kapsadığ unutulmamalıdır. Ayrıca derleme kapsamındaki çalışmaların küçük örneklemlerle yürütülmüş olmasının etkililik ve bırakma oranlarının düşük veya yüksek olması üzerinde etkili olabileceği düşünülmüştür. Bu durum, sonuçların kesinliği ve genellenebilirliği açısından soruna yol açabilir. Ayrıca alanyazında bırakmayı yordayan faktörler üzerine bir çalışmaya rastlanılmaması ve derlemeye dahil edilememesi de bir sınırlılık olarak görülmektedir.

Mevcut derlemenin belirtilen güçlü ve sınırlı yönlerinden hareketle bazı önerilerde bulunulabilir. Gelecekteki çalışmaların daha büyük örneklemlerle yürütülmesinin etkililik oranlarının daha iyi anlaşılması ve nedensellik ve bulguların genellenebilirliği açısından faydalı olacağı düşünülmektedir. Ayrıca EMDR'da tedaviye devam kararının yordayıcılarının yanında TSSB tanılı kişilerin EMDR tedavisi sırasında tedaviyi yarıda bırakma kararına neyin yol açtığının değerlendirilmesinin tedavi sürecinin planlanması açısından faydalı olabileceğine inanılmaktadır. Bu açıdan gelecekte EMDR'da tedavi bırakma kararının yordayıcıları üzerine odaklanılması önerilebilir. Ayrıca EMDR'ın etkililiğine ve etki mekanizmasına ilişkin daha fazla çalışma yürütülmesinin tekniğin TSSB tedavisinde kullanımı ve uygunluğunu destekleyebileceği düşünülmektedir.

\section{Kaynaklar}

Abbasnejad, M., Mahani, K. N., \& Zamyad, A. (2007). Efficacy of "eye movement desensitization and reprocessing" in reducing anxiety and unpleasant feelings due to earthquake experience. Psychological Research, 9(3), 104-111.

Acarturk, C., Konuk, E., Cetinkaya, M., Senay, I., Sijbrandij, M., Cuijpers, P., \& Aker, T. (2015). EMDR for Syrian refugees with posttraumatic stress disorder symptoms: Results of a pilot randomized controlled trial.cEuropean Journal of Psychotraumatology, 6, 1-9. doi: https://doi.org/10.3402/ejpt.v6.27414

Acarturk, C., Konuk, E., Cetinkaya, M., Şenay, I., Sijbrandij, M., Gulen, B., \& Cuijpers, P. (2016). The efficacy of eye movement desensitization and reprocessing for post-traumatic stress disorder and depression among Syrian refugees: Results of a randomized controlled trial. Psychological Medicine, 46, 2583-2593.doi: 10.1017/S0033291716001070

Amerikan Psikiyatri Birliği. (2013) Mental Bozuklukların Tanısal ve Sayımsal El Kitabı, Beşinci Baskı (DSM-V) (E. Köroğlu, Çev. ) Ankara: Hekimler Yayın Birliği.

Andrade, J., Kavanagh, D., \& Baddeley, A. (1997). Eye-movements and visual imagery: A working memory approach to the treatment of post-traumatic stress disorder. British Journal of Clinical Psychology, 36, 209-223. doi: 10.1111/j.20448260.1997.tb01408.x

Andrews, G. (1999). Efficacy, effectivenessandefficiency in mentalhealth service delivery. Australian \& New Zealand Journal of Psychiatry, 33, 316-322. doi:10.1046/j.1440-1614.1999.00581.x

Bal, F. (2020). Göz hareketleri ile duyarsizlaştırma ve yeniden işleme (EMDR) yönteminin psikolojik-psikiyatrik kökenli hastalıkların tedavisinde etkililiği: Sistematik derleme. Euroasia Journal of Social Sciences \& Humanities, 7(3), 110-116.

Balıbey, H., \& Balıkçı, A. (2013). Travma sonrası stres bozukluğu tanılı hastada göz hareketleri ile duyarsızlaştırma ve yeniden işleme (EMDR) tedavisi: Olgu sunumu. Düşünen Adam: Journal of Psychiatry \& Neurological Sciences, 26, 96-101. doi: 10.5350/DAJPN2013260111

Bandelow, B., \& Michaelis, S. (2015). Epidemiology of anxiety disorders in the 21 st century. Dialogues in Clinical Neuroscience, 17, 327-335.

Barron, I. G., Bourgaize, C., Lempertz, D., Swinden, C., \& Darker-Smith, S. (2019). Eye movement desensitization reprocessing for children and adolescents with posttraumatic stress disorder: A systematic narrative review. Journal of EMDR Practice and Research, 13, 270-283. doi: 10.1891/1933-3196.13.4.270 
Beer, R. (2018). Efficacy of EMDR therapy for children with PTSD: A review of the literature. Journal of EMDR Practice and Research, 12, 177-195. doi: 10.1891/1933-3196.12.4.177

Berg, D. P., de Bont, P. A., van der Vleugel, B. M., de Roos, C., de Jongh, A., Van Minnen, A., \& Van der Gaag, M. (2015). Prolonged exposure vs eye movement desensitization and reprocessing vs waiting list for post-traumatic stres disorder in patients with a psychoticdisorder: a randomized clinical trial. JAMA Psychiatry, 72, 259-267. doi: 10.1001/ jamapsychiatry.2014.2637

Bergmann, U. (2008). The neurobiology of EMDR: Exploring the thalamus and neural integration. Journal of EMDR Practice and Research, 2, 300-314. doi: 10.1891/1933-3196.2.4.300

Binay, H. (2016). Suriye ve Irak'tan gelen savaş mağduru çocuk ve genç mültecilerde travma sonrasi stres bozukluğu düzeyi (yayınlanmamış yüksek lisans tezi). Hasan Kalyoncu Üniversitesi, Gaziantep.

Bisson, J. I., Roberts, N. P., Andrew, M., Cooper, R., \& Lewis, C. (2013). Psychological therapies for chronic post-traumatic stress disorder (PTSD) in adults. The Cochrane Database of Systematic Reviews, 2013(12), CD003388.

Bradley, R., Greene, J., Russ, E., Dutra, L., \& Westen, D. (2005). A multidimensional meta-analysis of psychotherapy for PTSD. American Journal of Psychiatry, 162, 214-227. doi: 10.1176/appi. ajp.162.2.214

Brannock, D. (2020). Effectiveness of EMDR and CBT in children and adolescents with trauma (unpublished master thesis). Milligan University, Tennessee.

Breslau, N. (2002). Epidemiologic studies of trauma, posttraumatic stress disorder, and other psychiatric disorder. Canadian Journal of Psychiatry, 47, 923929.doi: 10.1177/070674370204701003

Cahill, S. P., Carrigan, M. H., \& Frueh, B.C. (1999). Does EMDR work? and if so, why: A critical review of controlled outcome and dismantling research. Journal of Anxiety Disorders, 13, 5-33. doi: 10.1016/S0887-6185(98)00039-5

Chen, L., Zhang, G., Hu, M., \& Liang, X. (2015). Eye movement desensitization and reprocessing versus cognitive-behavioral therapy for adult posttraumatic stress disorder: systematic review and meta-analysis. The Journal of Nervous and Mental Disease, 203, 443-451. doi: 10.1097/ NMD.0000000000000306

Cuijpers, P., Veen, S. C. V., Sijbrandij, M., Yoder, W., \& Cristea, I. A. (2020). Eye movement desensitization and reprocessing for mental health problems: A systematic review and meta-analysis. Cognitive
Behaviour Therapy, 49, 165-180. doi: doi.org/10.1 080/16506073.2019.1703801

Çak1l, G. (2018). Üniversite örnekleminde travma sonrası bilişler ile intihar olasılı̆̆ı arasındaki ilişki (Yayımlanmamış yüksek lisans tezi). İstanbul Gelişim Üniversitesi, İstanbul.

Davidson, P. R., \& Parker, K. C. (2002). Eye movement desensitisation and reprocessing is not better than exposure therapies for anxiety or trauma. Evidence-Based Mental Health, 5, 13-14. doi:10.1037//0022-006x.69.2.305

De Bont, P. A. J. M., Van der Vleugel, B. M., Van den Berg, D. P. G., De Roos, C., Smit, F., De Jongh, A.,...\& Van Minnen, A. (2019). Cost-effectiveness of prolonged exposure versus EMDR versus waiting list for the treatment of PTSD in patients with psychotic disorders. European Journal of Psychotraumatology, 10, 2411-2421.

De Jongh, A., Amann, B. L., Hofmann, A., Farrell, D., \& Lee, C. W. (2019). The status of emdr therapy in the treatment of posttraumatic stress disorder 30 years after it's introduction. Journal of EMDR Practice and Research, 13, 261-269 doi: 10.1891/1933-3196.13.4.261

Devilly, G. J., \& Spence, S. H. (1999). The relative efficacy and treatment distress of EMDR and a cognitive-behavior trauma treatment protocol in the amelioration of posttraumatic stress disorder. Journal of Anxiety Disorders, 13, 131-157. doi: 10.1016/S0887-6185(98)00044-9

Edmond, T., \& Rubin, A. (2004) Assessing the long-term effects of EMDR: Results from an 18-month follow-up study with adult female survivors of CSA, Journal of Child Sexual Abuse, 13, 69-86. doi: 10.1300/J070v13n01_04

Gradus, J. L. (2018). PTSD and death from suicide. PTSD Research Quarterly, 28, 1-8. doi: 10.1007/ s11920-018-0965-0

Grainger, R. D., Levin, C., Allen-Byrd, L., Doctor, R. M., \& Lee, H. (1997). An empirical evaluation of eye movement desensitization and reprocessing (EMDR) with survivors of a natural disaster. Journal of Traumatic Stress, 10, 665-671. doi: 10.1023/A:1024806105473

Gürel, D. (2004). Tıbbi tedaviye karş1 olumsuz tutum gösteren fiziksel ve ruhsal travmalı bir hastanın iki seanslık göz hareketleri ile duyarsızlaştırma ve yeniden yapılandırma tekniği ile iyileşme süreci. Türkiye Klinikleri Tıp Bilimleri Dergisi, 24(6), 689-696.

Hasin, D. S., Sarvet, A. L., Meyers, J. L., Saha, T. D., Ruan, W. J., Stohl, M., \& Grant, B. F. (2018). Epidemiology of adult DSM-5 major depressive disorder and its specifiers in the United States. JAMA Psychiatry, 75, 336-346. doi: 10.1001/jamapsychiatry.2017.4602 
Heber, R., Kellner, M., \& Yehuda, R. (2002). Salivary cortisoll evels and the cortisol response to dexamethasone before and after EMDR: A case report. Journal of Clinical Psychology, 58, 1521-1530. doi: 10.1002/jclp.10102

Hembree, E. A., Foa, E. B., Dorfan, N. M., Street, G. P., Kowalski, J., \& Tu, X. (2003). Do patients drop out prematurely from exposure therapy for PTSD. Journal of Traumatic Stress, 16, 555-562. doi: 10.1023/B:JOTS.0000004078.93012.7d

Hutchins, J., \& Clare, M. (2017). Treating a sexual abuse trauma with eye movement desensitisation and reprocessing therapy in an adult community mental health team setting: A case series. Psychology and Behavioral Science International Journal, 6, 1-5. doi: 10.19080/PBSIJ.2017.06.555676

Hurley, E. C. (2018). Effective treatment of veterans with PTSD: Comparison between intensive daily and weekly EMDR approaches. Frontiers in Psychology, 9, 1-10. doi: 10.3389/fpsyg.2018.01458

Ichii, M. (1997). Application of eye movement desensitization and reprocessing (EMDR) to survivors of the great Hanshin-Awaji earthquake: Treatment with less stress for stress disorder. Japanese Journal of Biofeedback Research, 24, 38-44.

Ilic, Z. (2004). EMDR in the treatment of posttraumatic stress disorder with prisoners of war. In Torture in war: Consequences and rehabilitation of victims. Yugoslav experience. (pp. 281-291). Belgrade: International Aid Network.

Ironson, G., Freund, B., Strauss, J. L., \& Williams, J. (2002). Comparison of two treatments for traumatic stress: A community-based study of EMDR and prolonged exposure. Journal of Clinical Psychology, 58, 113-128. doi: 10.1002/jclp.1132

İzci, F., \& Ünveren, G. (2017). Travma sonras1 stres bozukluğunda bilişsel davranışçı terapi ve göz hareketleri ile duyarsızlaştırma ve yeniden işleme. Bilişsel Davranışçı Psikoterapi ve Araştırmalar Dergisi, 6, 31-38. doi: 10.5455/JCBPR.236616

Jaberghaderi, N., Greenwald, R., Rubin, A., Zand, S. O., \& Dolatabadi, S. (2004). A comparison of CBT and EMDR forsexually-abused Iranian girls. Clinical Psychology and Psychotherapy, 11, 358-368. doi: 10.1002/cpp.395

Jensen, J. A. (1994). An investigation of eye movement desensitization and reprocessing (EMDR) as a treatment for posttraumatic stress disorder (PTSD) symptoms of Vietnam combat veterans. Behavior Therapy, 25, 311-326. doi:10.1016/S00057894(05)80290-4

Karadağ, M. (2020). Cinsel istismar mağduru kompleks travma sonrası stres bozukluğu olan kız ergenlerde grup EMDR uygulaması Psikiyatride Güncel Yaklaşımlar, 12, 1-6.

Karadag, M., Gokcen, C., \& Sarp, A. S. (2019). EMDR therapy in children and adolescents who have post-traumatic stress disorder: A six-week follow-up study. International Journal of Psychiatry in Clinical Practice, 24, 1-6. doi:10.1080/1365150 1.2019.1682171

Karatzias, T., Brown, M., Taggart, L., Truesdale, M., Sirisena, C., Walley, R.,... \& Paterson, D. (2019). A mixed methods, randomized controlled feasibility trial of eye movement desensitization and reprocessing (EMDR) plus standard care (SC) versus $\mathrm{SC}$ alone for DSM-5 posttraumatic stress disorder (PTSD) in adults with intellectual disabilities. Journal of Applied Research in Intellectual Disabilities, 32, 806-818.

Kessler, R. C., Chiu, W. T., Demler, O., \& Walters, E. E. (2005). Prevalence, severity, and comorbidity of 12-month DSM-IV disorders in the National Comorbidity Survey Replication. Archives of General Psychiatry, 62, 617-627. doi: 10.1001/archpsyc.62.6.617

Kilpatrick, D. G., Resnick, H. S., Milanak, M. E., Miller, M. W., Keyes, K. M., \& Friedman, M. J. (2013). National estimates of exposure to traumatic events and PTSD prevalence using DSM-IV and DSM-5 criteria. Journal of Traumatic Stress, 26, 537-547. doi: $10.1002 /$ jts. 21848

Koenen, K. C., Ratanatharathorn, A., Ng, L., McLaughlin, K. A., Bromet, E. J., Stein, D. J., ...\& Atwoli, L. (2017). Posttraumatic stress disorder in the world mental health surveys. Psychological Medicine, 47, 2260-2274. doi: 10.1017/S0033291717000708.

Konuk, E., Knipe, J., Eke, I., Yüksek, H., Yurtsever, A., \& Ostep, S. (2006). The effects of eye movement desensitization and reprocessing (EMDR) therapy on posttraumatic stress disorder in survivors of the 1999 Marmara, Turkey, earthquake. International Journal of Stress Management, 13, 291-308. doi:10.1037/1072-5245.13.3.291

Köhler, K., Eggert, P., Lorenz, S., Herr, K., Willmund, G., Zimmermann, P., \& Alliger-Horn, C. (2017). Effectiveness of eye movement desensitization and reprocessing in German Armed Forces soldiers with post-traumatic stress disorder under routine inpatient care conditions. Military Medicine, 182, 1672-1680. doi: 10.7205/MILMED-D-16-00307

Lancaster, G. A., Dodd, S., \& Williamson, P. R. (2004). Design and analysis of pilot studies: Recommendations for good practice. Journal of Evaluation in Clinical Practice, 10, 307-312. do$\mathrm{i}: 10.1111 / \mathrm{j} . .2002 .384$.doc.x 
Lancaster, C. L., Teeters, J. B., Gros, D. F., \& Back, S. E. (2016). Posttraumatic stress disorder: Overview of evidence-based assessment and treatment. Journal of Clinical Medicine, 5, 1-13. doi:10.3390/ jcm5110105

Lee, C., Gavriel, H., Drummond, P., Richards, J., \& Greenwald, R. (2002). Treatment of PTSD: Stress inoculation training with prolonged exposure compared to EMDR. Journal of Clinical Psychology, 58, 1071-1089. doi: 10.1002/jclp.10039

Lewis, C., Roberts, N. P., Gibson, S., \& Bisson, J. I. (2020). Dropout from psychological therapies for post-traumatic stress disorder (PTSD) in adults: Systematic review and meta-analysis. European Journal of Psychotraumatology, 11(1), 1-23.

Lewis, C., Roberts, N. P., Andrew, M., Starling, E., \& Bisson, J. I. (2020). Psychological therapies for post-traumatic stres disorder in adults: Systematic review and meta-analysis. European Journal of Psychotraumatology, 11, 172-196 doi:10.1080/20008 198.2020.1729633

Marcus, S. V., Marquis, P. ve Sakai, C. (1997). Controlled study of treatment of PTSD using EMDR in an HMO setting. Psychotherapy: Theory, Research, Practice, Training, 34, 307-315. doi: 10.1037/ h0087791

Mavranezouli, I., Megnin-Viggars, O., Daly, C., Dias, S., Welton, N. J., Stockton, S., ... \& Katona, C. (2020). Psychological treatments for post-traumatic stres disorder in adults: A network meta-analysis. Psychological Medicine, 50, 542-555. doi: 10.1017/ S0033291720000070

Moghadam, S., Kazemi, R., Taklavi, S., \& Naeim, M. (2020). Comparing the effectiveness of eye movement desensitization reprocessing and cognitive behavioral therapy in reducing post traumatic stress disorder. Health Psychology Report, 8, 3137. doi: 10.5114/hpr.2019.92305

Mukba, G., Tanriverdi, S., \& Tanhan, F. (2020). Investigation of the efficacy of EMDR in earthquake trauma: Case report. Cukurova University Faculty of Education Journal, 49, 477-500. doi: 10.14812/ cufej.567439

Najavits, L. M. (2015). The problem of dropout from "gold standard" PTSD therapies. F1000 Prime Reports, 7, 1-8. doi:10.12703/P7-43

National Institute for Clinical Excellence (NICE). (2005). The management of PTSD in adults and children in primary and secondary care. Wilshire, United Kingdom: Cromwell Press.

Önsüz, M. F., Topuzoğlu, A., İkiışık, H., \& Karavuş, M. (2009). Marmara depreminden altı y1l sonra Sapanca'da travma sonrası stres ve anksiyete bozukluk- larının değerlendirilmesi. Yeni Symposium, 47 (4), 164-177

Özçetin, A., Maraş, A., Ataoğlu, A., \& İçmeli, C. (2008). Deprem sonucu gelişen travma sonrası stres bozukluğu ile kişilik bozuklukları arasında ilişki. Düzce Tıp Fakültesi Dergisi, 10(2), 8-18.

Özgen, F., \& Aydın, H. (1999).Travma sonrası stres bozukluğu. Klinik Psikiyatri, 2(1), 34-41.

Piyavhatkul, N., Paholpak, S., \& Boonpromma, W. (2018). Effectiveness of trauma therapy and EMDR in patients with psychiatric in Northeastern Thailand. International Journal of Medical Research \& Health Sciences, 7(12), 7-17.

Power, K., McGoldrick, T., Brown, K., Buchanan, R., Sharp, D., Swanson, V., \& Karatzias, A. (2002). A controlled comparison of EMDR versus exposure plus cognitive restructuring versus waiting list in the treatment of post-traumatic stress disorder. Clinical Psychology \& Psychotherapy, 9 299-318. doi: 10.1002/cpp.341

Ramsawh, H. J., Fullerton, C. S., Mash, H. B. H., Ng, T. H. H., Kessler, R. C., Stein, M. B., \& Ursano, R. J. (2014). Risk for suicidal behaviors associated with PTSD, depression, and their comorbidity in the US Army. Journal of Affective Disorders, 161, 116-122. doi: 10.1016/j.jad.2014.03.016

Reinders, L. A. (2019). Dropout in the treatment of PTSD: a systematic review and meta-analysis (unpublished Master's thesis) University of Twente, Holland

Rothbaum, B. O. (1997). A controlled study of eye movement desensitization and reprocessing in the treatment of posttraumatic stress disordered sexual assault victims. Bulletin of The Menninger Clinic, 61(5), 317-333.

Rothbaum, B. O., Astin, M. C., \& Marsteller, F. (2005). Prolonged exposure versus eye movement desensitization and reprocessing (EMDR) for PTSD rape victims. Journal of Traumatic Stress: Official Publication of The International Society for Traumatic Stress Studies, 18, 607-616. doi: 10.1002/ jts. 20069

Rubin, A. (2003). Unanswered questions about the empirical support for EMDR in the treatment of PTSD: A review of research. Traumatology, 9, 4-30.

Russell, M. C. (2008). Treating traumatic amputation-related phantom limb pain: A case study utilizing eye movement desensitization and reprocessing within the armed services. Clinical Case Studies, 7, 136153. doi: 10.1177/1534650107306292

Russell, M. C., \& Figley, C. R. (2013). Treating traumatic stress injuries in military personnel: An EMDR practitioner's guide. Abingdon: Routledge Press. 
Sagaltici, E., Alpak, G., \& Altindag, A. (2020). Traumatic life events and severity of posttraumatic stress disorder among Syrian refugees residing in a camp in Turkey, Journal of Loss \& Trauma, 25, 1-14 doi: 10.1080/15325024.2019.1654691

Schnyder, U. (2005). Why new psychotherapies for posttraumatic stress disorder?. Psychotherapy and Psychosomatics, 74, 199-201. doi: 10.1159/000085142

Schottenbauer, M. A., Glass, C. R., Arnkoff, D. B., Tendick, V., \& Gray, S. H. (2008). Nonresponse and dropout rates in outcome studies on PTSD: Review and methodological considerations. Psychiatry: Interpersonal and Biological Processes, 71(2),134168.

Shapiro, F. (1989). Efficacy of the eye movement desensitization procedure in the treatment of traumatic memories. Journal of Traumatic Stress, 2, 199. 223. doi: $10.1002 /$ jts. 2490020207

Shapiro, F. (2002). EMDR 12 years after its introduction: Past and future research. Journal of Clinical Psychology, 58 1-22. doi:10.1002/jclp.1126

Sinici, E., Maden, Ö., Ak, M., Bozkur, A., \& Özşahin, A. (2012). Bir cinsel tecavüz vakasında EMDR uygulaması: Vaka sunumu. Yeni Symposium, 50(1), 58-60.

Slotema, C. W., van den Berg, D. P., Driessen, A., Wilhelmus, B., \& Franken, I. H. (2019). Feasibility of EMDR for post traumatic stres disorder in patients with personality disorders: A pilot study. European Journal of Psychotraumatology, 10, 1-10. doi: 10.1080/20008198.2019.1614822

Stanbury, M., Drummond, P. D., Laugharne, J., Kullack, C., \& Lee, C. W. (2020). Comparative efficiency of EMDR and prolonged exposure in treating posttraumatic stress disorder: A randomized trial. Journal of EMDR Practice and Research, 14, 2-12. doi: 10.1891/1933-3196.14.1.2

Stickgold, R. (2002). EMDR: A putative neurobiological mechanism of action. Journal of Clinical Psychology, 58, 61-75. doi: 10.1002/jclp.1129

Tokgöz, Z. A. (2018). Göz hareketleri ile duyarsızlaştırma ve yeniden işleme (EMDR). Mehmet Akif Ersoy Üniversitesi Eğitim Fakültesi Dergisi, 47, 526-545. doi:10.21764/maeuefd.360722

Trentini, C., Lauriola, M., Giuliani, A., Maslovaric, G., Tambelli, R., Fernandez, I., \& Pagani, M. (2018). Dealing with the aftermath of mass disasters: A field study on the application of EMDR integrative group treatment protocol with child survivors of the 2016 Italy earthquakes. Frontiers in Psychology, 9, 1-13. doi: 10.3389/ fpsyg.2018.00862
Van den Hout, M., Engelhard, I.M., Smeets, M.A.M., Horsnveld, H., Hoogeveen, E., Heer, E., ... Rijkeboer, M.M. (2010). Counting during recall: Taxing of working memory and reduced vividness and emotionality of negative memories. Applied Cognitive Psychology, 24, 303-311. doi: 10.1002/acp.1677

van der Kolk, B. A., Spinazzola, J., Blaustein, M. E., Hopper, J. W., Hopper, E. K., Korn, D. L., \& Simpson, W. B. (2007). A randomized clinical trial of eye movement desensitization and reprocessing (EMDR), fluoxetine, and pill placebo in the treatment of posttraumatic stress disorder: treatment effects and long-term maintenance. Journal of Clinical Psychiatry, 68, 1-11. doi: 10.4088/jcp. v68n0105

Wagenmans, A., Van Minnen, A., Sleijpen, M., \& De Jongh, A. (2018). The impact of childhood sexual abuse on the outcome of intensive trauma-focused treatment for PTSD. European Journal of Psychotraumatology, 9(1), 1-12.

World Health Organization (2013). WHO releases guidance on mental health care after trauma. Saudi Medical Journal, 34(9), 975.

Wilson, G., Farrell, D., Barron, I., Hutchins, J., Whybrow, D., \& Kiernan, M. D. (2018). The use of Eye-Movement-desensitization-reprocessing (EMDR) therapy in treating post-traumatic stress disorder: A systematic narrative review. Frontiers in Psychology, 9, 1-11.

Wise, L. A., Zierler, S., Krieger, N., \& Harlow, B. L. (2001). Adult onset of major depressive disorder in relation to early life violent victimisation: a case-control study. The Lancet, 358, 881-887. doi:10.1016/S0140-6736(01)06072-X

Wittchen, H. U., Jacobi, F., Rehm, J., Gustavsson, A., Svensson, M., Jönsson, B., ...\& Fratiglioni, L. (2011). The size and burden of mental disorders and other disorders of the brain in Europe 2010. European Neuropsychopharmacology, 21, 655679. doi: 10.1016/j.euroneuro.2011.07.018

Yurtsever, A., Konuk, E., Akyüz, T., Zat, Z., Tükel, F., Çetinkaya, M., ... \& Shapiro, E. (2018). An eye movement desensitization and reprocessing (EMDR) group intervention for Syrian refugees with post-traumatic stress symptoms: Results of a randomized controlled trial. Frontiers in Psychology, 9, 1-8. doi: 10.3389/fpsyg.2018.00493 


\section{Summary \\ Review of Studieson The Effectiveness of EMDR Applicationsin Post-Trauma Stress Disorder}

\author{
Alperen Güçlü \\ Ankara Yıldırım Beyazıt University
}

Eye Movement Desensitization and Reprocessing Systematic desensitization and processing (EMDR) with eye movements is a relatively new therapy technique that has become popular in the treatment of post-traumatic stress disorder (PTSD) in recent years. The technique, developed by Shapiro in 1987, is used to process memories of the traumatic event. Trauma victim follows the therapist's fingers simultaneously while talking about the traumatic event (Shapiro, 1989, 2002). Shapiro has developed EMDR in line with his personal experience and realized that it can be effective in trauma treatment (Rubin, 2003). After his discovery, many researchers have started to investigate the effectiveness of EMDR on other disorders, and it has been determined that many disorders such as depression, anxiety disorders and even personality disorders can be effective in the treatment process (De Jongh, Amann, Hoffman, Farrel \& Lee, 2019; Karadağ, 2020). However, it is claimed that induction with eye movements presented in EMDR can be very effective especially in the processing of traumatic memories in PTSD (Shapiro, 2002). It is claimed that trauma symptoms such as intense anxiety emotional distress, event related returns, restlessness and hypersensitivity to stimulants can recover rapidly (e.g., Van den Hout et al., 2010).

Despite the claims that EMDR can eliminate PTSD symptoms by processing traumatic memories, when EMDR was first proposed, some researchers approached the technique with suspicion and They suggested that current therapy techniques such as cognitive behavioral therapy (CBT) may be more effective in resolving trauma memories. Therefore they suggested current therapy techniques instead of EMDR. (Devilly \& Spence, 1999; Heber Kellner \&Yehuda 2002). Some researchers have also stated that EMDR may not differ from other techniques (Davidson \& Parker, 2002). In this respect, there is an existing duality regarding the use of EMDR in general. Although there are researchers who argue that EMDR may be more effective than other techniques for

\author{
Özden Yalçınkaya Alkar \\ Ankara Yıldırım Beyazıt University
}

the treatment of PTSD (e.g.,Lee, Gavriel, Drummond, Richards \& Greenwald, 2002; Stanbury, Drummond,Laugharne, Kullack \&Lee, 2020), there are also researchers who argue that the technique is not as effective as claimed. This creates question marks about the use of the technique. Is EMDR really an effective intervention method in PTSD treatment as Shapiro suggests? Answering this question seems to be important in terms of PTSD treatment process and eliminating doubts about EMDR. In this context, it may be useful to review the studies on the use of EMDR in the treatment of PTSD (Shapiro, 1989).

The first research on the use and impact level of EMDR in PTSD, was done by Shapiro (1989), who developed the technique. Studies by Shapiro have shown that the technique can quickly improve PTSD symptoms. These initial studies have led many researchers to work on EMDR. Lee et al. (2002) reported that traumatic symptoms of trauma victims improved within three sessions on average, and other problems related to trauma could be eliminated to a great extent. Similar to this finding, later studies reported that EMDR can improve not only trauma symptoms but also depressive symptoms and anxiety symptoms.(Edmond \& Rubin, 2003; Sinici, Maden, Ak, Bozkurt \& Özşahin, 2012). In addition, researchers such as Bal (2020) and Hurley (2018) reported that the improvement achieved in people treated with EMDR was maintained after the treatment.

Contrary to studies showing that EMDR can be an effective and usable intervention, some research findings also reported minor effect levels for EMDR. Devilly and Spence (1999) divided the participants diagnosed with PTSD into two categories and applied CBT in half and EMDR in the other half. At the end of the study, it was reported that the effect level of EMDR was very low (\%25-30) and the participants showed the trauma symptoms again during the follow-up period. This study is one of the studies reporting the smallest effect size regarding the effectiveness of EMDR. Haber et al (2002)

Address for Correspondence: Alperen Güçlü, Ankara Yıldırım Beyazıt University, Faculty of Humanities and Social Sciences, Department of Psychology, Esenboğa Merkez Külliyesi Dumlupınar Mah. Küme Evleri No:1/1 A Blok Kat:3 06760 Çubuk / Ankara

E-mail: alperenguclu5@gmail.com 
reported similar results. In some of these studies, the traumatic event causing PTSD was chronic, and there were disorders accompanying PTSD. Van der Kolk et al. (2007) stated that this type of situations may decrease the effectiveness of EMDR. He reported that EMDR is effective but the some conditions are effective on the result.

When evaluated on the basis of the EMDR study findings, the results regarding the effect level of EMDR are complicated. Some studies reported higher, almost $100 \%$ recovery rates (De Jongh et al., 2019; Karadag, Gokcen ve Sarp, 2019; Konuk et al., 2006), while others reported lower effect levels (e.g., Jensen, 1994; Rothbaum et al., 2005). However, a common result of the studies is that EMDR can benefit to a certain extent in improving PTSD symptoms. However, one of the important issues about EMDR is how EMDR works, namely how it treats trauma symptoms (Davidson \& Parker, 2002). The mechanism of EMDR has not been fully explained. Even Shapiro (1989), has not been able to propose a definitive mechanism for how treatment takes place.Although some experts make some suggestions on this subject each of these is an assumption.Researchers explained the effect of EMDR on the basis of neurobiological processes, which include many brain structures and processes(e.g., Andrade, Kavanagh \& Baddeley, 1997). Despite some differences, the common emphasis is that eye movements trigger some neurobiological processes, so trauma symptoms can can be processed. Although there are some exceptions (e.g., Cahill, Carrigan \& Freuh, 1999), researchers found that the use of eye movements is very effective (Karadağ, 2020).

Although EMDR's mechanism of action has not yet been clarified, it is stated that the use of eye movements provides benefits. This make think whether the use of eye movements would be effective in every traumatic event. People can face many traumatic events such as war, cancer, traffic accident, natural disaster, harassment throughout their lives (Ilic, 2004; Rothbaum, 1997). Not everyone is affected by these events in the same way, some people can overcome these situations quickly, while others can develop PTSD (Binay, 2016; Trentini et al., 2018). It is important how effective EMDR can be in the treatment of PTSD developing due to these different events. When the studies in the literature are examined, EMDR has been seen to be similarly effective in the treatment of PTSD developing as a result of different events. (Abbasnejad, Mahani \& Zamyad, 2007; Acarturk et al, 2015; Mukba, Tanrıverdi ve Tarhan, 2020). Such study findings may seem to support the applicability of EMDR.

In the literature, treatment drop-out rates regarding the effectiveness and usability of EMDR in PTSD treatment are also mentioned. Studies mostly reported low dropout rates (\%10-15) for EMDR. (e.g., Hurley, 2018; Schottenbauer, Glass, Arnkoff, Tendick \& Gray, 2008). On the other hand, there are studies that report higher drop-out rates. Nijdam, Gersons, Reitsma, de Jongh and Olff (2012) reported that drop-out rates could reach $\% 30$. In addition, the researchers compared EMDR dropout rates with other treatment techniques in PTSD treatment. Although some studies report that there is no significant difference between techniques (e.g., Berg et al., 2015), in many studies on the subject, dropout rates are lower in EMDR compared to other techniques (Reinders, 2019). This situation raised the question of why there are lower dropout rates in EMDR despite the some exceptional. Researchers attributed this to the fact that EMDR is more easily tolerated by trauma victims due to some of its features. In this subject, researchers have emphasized that the technique does not include intense exposure sessions, it affects quickly, does not include homework and is cost-effective (De Bont et al., 2019; Schnyder, 2005; Karadag et al., 2019).

\section{Discussion}

The findings of the study on the use of EMDR in PTSD treatment, although there are certain exceptions (e.g., Jensen, 1994) generally seem to support the availability and effectiveness of EMDR applications in PTSD treatment (Acarturk et al., 2016; Moghadam, Kazemi, Taklavi \& Naeim, 2020). According to the findings of this study, while speaking on the traumatic event, following the therapist's finger movements simultaneously helps to process the traumatic memories (Shapiro, 1989) This can improve symptoms associated with PTSD. In addition, with the improvement of trauma symptoms, it has been reported that depressive symptoms may reduce and anxiety level may decrease, and functionality can become more functional (e.g., Sinici, et al., 2012) In this respect, based on the findings of the study regarding the use of EMDR in PTSD treatment, it can be stated that the use of EMDR in PTSD provided "two birds with one stone".

An important issue regarding the use of EMDR is how the technique can achieve a certain degree of improvement. How can EMDR improve symptoms of trauma? This question has not been answered clearly yet (Tokgöz, 2018; Van den Hout et al., 2010). Considering the study findings in the field, it can be thought that eye movements provide improvement, but the basic logic of eye movements is not understood.Many researchers approached this question on the basis of neurobiological explanations (e.g., Bergman, 2008; Stickhold, 2002) This makes sense on the basis of the idea that PTSD is actually a problem with the processing of traumatic me- 
mories in memory, as Shapiro also shows. It may be useful to identify the factors that affect the change process in terms of neurobiology. It is thought that the increase in brain imaging and research in recent years may be useful in this regard.

Within the scope of this study, the findings of the study regarding the effect level of EMDR in different traumatic disorders related to the effectiveness of EMDR are also included. When evaluated on the basis of studies on victims of natural disasters, warfare and sexual harassment, it has been seen that EMDR can be similarly effective in different traumatic events (Abbasnejad et al., 2007; Wagenmans, Van Minnen, Sleijpen ve De Jongh, 2018). In this respect, it can be thought that EMDR can affect traumatic events independent of the traumatic event. However, it is not clear which traumatic events have a higher effect level. It is thought that the absence of any study on people who have experienced different traumatic events on this situation may be effective. The studies to be carried out considering the severity of the traumatic event, the duration of the event, the personality characteristics of the victim of trauma can show that EMDR can be used effectively on which type of trauma. In addition, the drop-out rates of treatment regarding the applicability of the technique were also discussed. Despite some exception overall (e.g.,Slotema, van den Berg, Driessen, Wilhelmus \& Franken 2019) studies have reported low drop-out rates (Acarturk et al., 2015; Hembree et al., 2003). Therefore, the researchers made assumptions about what influenced the decision to continue treatment (e.g., Schnyder, 2005) However, as mentioned in the article, there are also findings of study where quitting rates can be high, so it seems important to investigate the reasons for quitting. On the other hand, no related study has been found in the related literature. This situation is seen as an important deficiency in the use of EMDR. Evaluating the factors predicting the drop-out of the treatment and planning the treatment process with attention to these may increase the effectiveness of EMDR. In this context, this situation should be considered.

In conclusion, many aspects related to EMDR use in PTSD treatment have been evaluated within the scope of the current review. The review is thought to be important because it brings together many different points. In addition to the current study findings, early studies are also included. Future research may explore different points related to EMDR and PTSD, which are not addressed in this article. This can be useful for better understanding of the place of EMDR applications in PTSD treatment. 